Article available at nttp://WWw.parasite-journal.org or nitp://dx.dol.org/10.1051/parasite/1996031003

\title{
RECENT DEVELOPMENTS AND RATIONALE TOWARDS NEW STRATEGIES FOR MALARIAL CHEMOTHERAPY
}

\author{
VIAL H.*
}

\section{Summary :}

The major problem facing world research for new antimalarials lies in encountered difficulties in the search for new promising paths. The past 20 years have witnessed a very impressive increase in our understanding of the biochemistry and molecular biology of malaria parasites, with attention focused on specific parasite molecules that are keys to the parasite life cycle or the induction of its pathogenesis. Directed pharmacology research has involved the identification and characterization of targets that can be specifically pharmacologically affected, including the replicating machinery of the parasites, various metabolisms such as the purine salvage pathway, and biosynthesis of pyrimidines or phospholipids. Protease inhibitors (e.g. those degrading haemoglobin), the use of iron chelators or inhibition of heme polymerization, induction of oxidative stress or inhibition of antioxidant enzymes are also investigated. Some pathways have already been validated with current antimalarials but, due to the development of resistance, complete characterization of the molecular structure of the target should allow attack of these exceptional molecules at novel and distinct sites with new drug concepts. The problem in the quest to develop new antimalarials is the fact that the results are not being materialized, but there is no lack of pharmacological targets.

KEY WORDS : antimalarials, molecular structure of the target, replication, purine, pyrimidine, phospholipid, new drug concepts.

\section{INTRODUCTION}

$\mathrm{V}$ iewed globally, parasitic diseases pose an increasing threat to human health and welfare. In the last 25 years, malaria has regained its former position as the greatest threat to the health and economic prosperity of mankind. The rising costs of insecticides, the development of resistance to organochlorines, such as DTT, and the spreading resistance of Plasmodium falciparum to most available drugs can be held responsible for this depressing picture. The development of a vaccine against malaria has so far not fulfilled expectations in field trials (Maurice, 1995; Tanner et al., 1995). Differences in the biology of major malaria vectors preclude the development of

\footnotetext{
* Dynamique Moléculaire des Interactions Membranaires, CNRS URA 1856, Université Montpellier II, Case 107, Place Eugène-Bataillon, 34095 Montpellier Cedex 5, France.

Tel.: (33) 671437 45. Fax: (33) 67144286

e-mail: vial@univ-montp2.fr
}

Résumé : RÉCENTS DÉVELOPPEMENTS ET CONCEPTS POUR DE NOUVELLES STRATÉGIES ANTIPALUDIQUES

Le problème majeur dans la lutte antipaludique réside dans la difficulté à découvrir de nouvelles voies thérapeutiques. Des progrès fantastiques dans la biochimie et la biologie moléculaire du parasite ont été réalisés au cours des 20 dernières années, et ont révélé des éléments-clés indispensables pour la vie du parasite ou pour l'établissement de sa pathologie. La pharmacologie dirigée implique l'identification et la caractérisation de cibles qui puissent être sélectivement affectées. Ceci inclue la machinerie de réplication du parasite, ou des métabolismes comme la voie de récupération des purines, la biosynthèse des pyrimidines ou des phospholipides. Les inhibiteurs de protéases, dont celles effectuant le catabolisme de l'hémoglobine, l'utilisation de chélateur du fer, l'inhibition de la polymérisation de l'hème, l'induction d'un stress oxydatif ou la perturbation des défenses contre le stress oxydatif sont aussi examinés. Des principes actifs ont été largement validés sur le terrain, mais, en raison du développement des résistances, une connaissance complète de la structure moléculaire de leur cible permettrait une attaque avec un nouveau concept de drogue interagissant à des sites distincts avec la cible. De fait, le développement d'une nouvelle pharmacologie antipaludique ne souffre pas du manque de cibles pharmacologiques potentielles, mais d'un manque de concrétisation.

MOTS CLÉS : lutte antipaludique, structure moléculaire des cibles, réplication purines, pyrimidine, phospholipides, principes actifs.

simple, universally applicable strategies for malaria control (Collins et al., 1995). Consequently, curative or preventive chemotherapy of malaria remains the essential arm in the battle against this major endemic disease.

The past 20 years have witnessed a very impressive increase in our knowledge of plasmodial biology. Recent advances in our understanding of the biochemistry and molecular biology of these organisms have focused attention on specific parasite molecules that are essential keys to the parasite life cycle or pathogenesis of the disease. The relevant literature has been reviewed at regular intervals (Holz, 1977; Sherman, 1979; Sherman, 1984; Ginsburg, 1990; Vial et al., 1992; Elford et al., 1995; Olliaro et al., 1995). This report summarizes potentially unique parasite characteristics that have provided valid pharmacological targets or may provide targets for the development of future chemotherapeutics. Here, we only touch upon portions of this broad field that show promise for practical applications. We are specially interested in the more perilous $P$. fal- 
ciparum malaria since parasitemia goes up until the host's death and whose feared complication is cerebral malaria. The nonerythrocytic stages of malaria parasites, including sporozoites, exoerythrocytic liver stages, sexual gametocyte stages and all mosquito stages, are difficult to study and specific information regarding these stages is still scarce.

\section{CURRENT ANTIMALARIAL DRUGS}

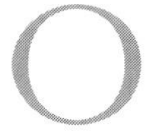

nly asexual erythrocytic parasites produce clinical illness. Neither persistent exoerythrocytic hepatic parasites (hypnozoites) nor sexual parasites (gametocytes) produce recognizable clinical symptoms. Antimalarial agents that inhibit the replication of asexual erythrocytic parasites thus provide the most rapid clinical improvement. The oldest recognized antimalarial agent (quinine), the antimalarial agents used in World II (chloroquine and quinacrine), and newer agents used for chloroquine resistant P. falciparum (mefloquine and halofantrine), have amino-substituted or methanolic substituted multiring structures. Two other structural classes, dihydrofolate reductase (e.g. pyrimethamine), and p-aminobenzoic analogues (e.g. sulfadoxine) are used in combination. Other important drugs include inhibitors of protein synthesis (e.g. tetracycline and doxycycline). Although toxic side effects are a major drawback in its use, the 8-aminoquinoline primaquine, which was introduced in 1952 , is used to treat the other parasite stages (exoerythrocytic and sexual erythrocytic parasites) and remains the most effective agent for the radical cure of P. vivax malaria (Werndorfer et al., 1991; White, 1992).

The increasing capacity of malaria parasites to resist chemotherapy causes a frightening deterioration in the efficacy of conventional antimalarial drugs. Resistance concerns the two main series of blood schizonticides, lysosomotropic agents and the antifol combination group with a rapid worldwide spread (Werndorfer \& Payne, 1991). Indeed, malaria pathogens are highly adaptable to chemical changes in their environment. Following introduction of a new drug, it can be anticipated that P. falciparum will develop resistance within a few years. At present time, there is no agent that can offer protection against malaria in all regions of the world; the need for novel chemotherapeutic agents is therefore acute. Drugs now being developed include artemisinin derivatives, pyronaridine (both originally developed in China), new antifolate combinations, atovaquone and a new 8-aminoquinoline. Some of these drugs may become available within the next few years (Olliaro et al., 1995). Resistance modifiers that restore the effectiveness of present first line antimalarial drugs would be of great practical interest, but no compounds have yet proven effective at therapeutic doses.

\section{PHARMACOLOGICAL STRATEGY}

everal natural products isolated from plants used in traditional medicine have potent antiplasmodial action in vitro and represent potential sources of new antimalarial drugs. The clinical efficacy of artemisinin demonstrates that quinine is not the sole antimalarial drug obtainable from the plant kingdom. Nevertheless, these points will not be discussed below. Many other plant constituents have antimalarial activities and could give rise to new antimalarial drug concepts (Phillipson, 1994). There are often difficulties in synthesizing de novo the drugs on a commercial scale, and improving the activity through hemisynthetic compounds. Moreover, in a number of cases, there is cross-resistance with currently used antimalarials.

A necessary first step is to identify a molecular target critical to the disease process; infectious pathogens are particularly suited for the exploitation of divergent or completely novel metabolic pathways. The pharmacological target must be implicated in the life cycle of the infectious agent, in its pathogenesis or virulence. Identifying these molecules and determining their exact functions require fundamental research on the infectious agents with respect to their internal biochemistry, interactions with their hosts, and pathological organisms. Another step is to determine how crucial the target molecule is for the pathogenic agent or the pathological process. This is of utmost importance since the ensuing exercise work is very time and money-consuming.

Secondly, pharmacology is synonymous with selectivity, and hence requires identification of biochemical processes that could be selectively disrupted by utilizing differences between host and parasite proteins for designing drugs. Most of the enzymes have become well adapted to regulate specific metabolic needs of the malaria parasite during its asexual or sexual stages. Drugs are usually directed at residues that are essential for parasitic functions, such as substrate-binding site residues of enzymes. Unfortunately, most amino acid residues implicated in substrate and coenzyme binding and catalysis are often found to be highly conserved. It is therefore necessary to identify rare and unique regions in the protein sequences. Amino acid insertions and deletions are often observed allowing a detailed understanding of unique features of the active site for this complex life cycle of malaria parasites.

The next step is, if possible, full characterization of the molecular structure of the target. A number of plas- 
modial molecules have been purified, but their characterization has been hampered by the very low quantities available, inviting approaches using molecular cloning techniques. Gene cloning combined with the expression of engineered genes encoding $P$. falciparum proteins permit more detailed structure function studies of parasite proteins and could potentially help in developing specific antimalarial drugs. The structures of fewer than $1 \%$ of the proteins have been characterized by X-ray crystallography or multidimensional NMR spectroscopy. De novo prediction of protein structures based on primary sequences is still insufficiently accurate and will require conceptual advances in the understanding at protein folding. Homology-based modeling is an attractive approach that circumvents the absence of empirical structural data, as reasonable assumptions are made regarding structural conservation. Another advantage of this approach is the relatively high structural conservation in the immediate vicinity of the active sites of homologous enzymes, but this is also a disadvantage since this part of the enzyme is often the target of pharmacological agents.

With an experimental or hypothetical structure in hand, the challenge is to find a complementary structure that can be translated into a good ligand or antagonist. The ultimate objective is to generate novel structures as potential lead compounds (Sun et al., 1993). It would be ideal to develop drugs with high affinity and selectivity, and these agents could be administered in about stoechiometric amounts relative to their ligands. The law of mass action dictates interaction of reversibly binding inhibitors. It follows that the free drug concentration must be at 100 -fold the $\mathrm{K}_{\text {diss }}$ to inhibit the target greater than $99 \%$ the target. Drug designs should focus on inhibitors with a $\mathrm{K}_{\text {diss }}$ of less than $10^{-8} \mathrm{M}$, otherwise the drug concentration must be very high to sustain the inactive complex, which could lead to an unacceptable dosage regimen (Schirmer et al., 1995). Affinity of the ligand for the target involves numerous negative and positive interactions; the GibbsHelmholtz equation gives the free energy of ligand binding to macromolecules (Andrews, 1986; Schirmer et al., 1995). The free energy change, $\Delta G$ associated with a drug receptor, is related to the equilibrium constant $\mathrm{K}$ for the interaction as set out by the equation: $\Delta \mathrm{G}=-2.303 \mathrm{RT} \log \mathrm{K}$. Increasing the affinity of the ligand for the target usually requires reinforcement of the interactions through ionic, hydrogen and van der Waals bonds (Andrews, 1986), in order to generate compounds of sufficient potency to serve as leads in new drug development.

\section{NUCLEIC ACID SYNTHESIS}

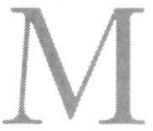

alaria parasites require purine and pyrimidine for DNA and RNA synthesis. Targeting at this level is extremely harmful since it is particularly crucial for the life transmission in every organisms. However, specific plasmodial requirements have already led to the development of invaluable antimalarial drugs. Further characterization of the whole system will probably provide other selective targets in the future.

\section{DNA REPLICATION}

One such target could be the DNA synthesis rate limiting enzyme ribonucleotide reductase (EC 1.17.4.1; RNR) that maintains in an allosterically controlled way, a continuous balanced supply of 2'-deoxyribonucleotides dNTPs for replication and repair of DNA by the reduction of ribonucleotides (Smeijsters et al., 1994). RNR are heterodimeric enzymes with an $\alpha 2 \beta 2$ configuration, and containing ferric ion which is essential for their activity. cDNA encoding both the large $\left(\mathrm{pfR}_{1}\right)$ and small $\left(\mathrm{pfR}_{2}\right)$ RNR subunits of P. falciparum were recently cloned simultaneously by two groups (Chakrabarti et al., 1993; Rubin et al., 1993). In contrast to mammalian ribonucleotide reductase, pfR1 and pfR2 genes are located on the same chromosome. The large subunits were found to have $67 \%$ of identity with human large subunits. The small regulatory subunit that contains the major catalytic motif consisting of a tyrosyl radical and a dinuclear Fe site, shares $59 \%$ amino acid identity, suggesting a difference in allosteric regulation of the P. falciparum enzyme from its human host. A striking sequence divergence between human R2 and PfR2 at the C terminus may provide a selective target for inhibition of the malarial enzyme (Rubin et al., 1993). Transcription peaks preceding maximal DNA synthesis activity, but mRNA accumulation for the two subunits shows different temporal patterns during the cell cycle (Chakrabarti et al., 1993; Rubin et al., 1993). Interestingly, a 20-mer antisense phosphorothioate oligonucleotide complementary to sequences around the translational initiation codon of the small subunit show significant inhibition of growth at $1 \mu \mathrm{M}$ (Chakrabarti et al., 1993), while a synthetic oligopeptide corresponding to the seven C-terminal residues of PfR2 selectively inhibits malarial R2 (Rubin et al., 1993). However, the former experiments must be interpreted cautiously since non-sequence specific exogenously phosphodiester or phosphothioate oligodeoxynucleotides also exert an effect on $P$. falciparum proliferation at micromolar concentration through an effect on red blood cell invasion (Clark et al., 1994). 
DNA polymerases (pol) are essential components of chromosomal DNA replication in eukaryotic cells. Pol $\alpha, \delta$ and $\varepsilon$ are involved in replication of chromosomal DNA, while pol $\gamma$ replicates mitochondrial DNA and pol $\beta$ is involved in DNA repair (Wang, 1991). Several distinct DNA polymerases have been characterized in Plasmodium (Chavalitshewinkoon et al., 1993) but assays for specific gene products still have to be developed. DNA pol $\alpha$ is one of the most divergent proteins reported so far, with $14-17 \%$ identity with other organisms (White et al., 1993). The acyclic nucleotide analogue HPMPA ((S)-9-(3-hydroxy-2-phosphonylmethoxypropyl) adenine) is active against several viral infections, and DNA polymerases are presumed to be the target. It is a very effective and selective antimalarial compound $\left(\mathrm{IC}_{50}\right.$ of $40 \mathrm{nM}$ ), that abruptly arrests $P$. falciparum-cultured schizonts. Nevertheless, various experiments indicated that the antimalarial action could not be mediated through DNA polymerase, or RNR inhibition, or through its use as alternative substrate for plasmodial polymerase (Smeijsters et al., 1994). Enzymes responsible for topological control of DNA were also found to be successful targets (Riou et al., 1986), but anticancer drugs are not appropriate for an eventual use as antimalarials. However, substitution of the acridine ring of 9-anilinoazaacridine confers lower mammalian cytotoxicity and much higher antiparasitic activity, with positive relationships between the in vitro antimalarial activity and their ability to inhibit the parasite topoisomerase II (Gamage et al., 1994). Detailed information on the replicating machinery of malaria parasites will guide the search for specific inhibitors.

\section{Purine SAlvage Pathway}

The pathways by which parasitic protozoa and their human hosts synthesize purine nucleotides might constitute the most striking metabolic discrepancy. While animal cells and tissues can generate the purine ring de novo from amino acids and 1-carbon moieties, parasitic protozoa are auxotrophic for purines. The intraerythrocytic stage of Plasmodium contains a unique series of enzymes that enable it to scavenge adenosine, inosine, hypoxanthine and xanthine from the host (hypoxanthine could be a preferred substrate). Plasmodium thus mainly relies on phosphoribosyltransferase (PRT), which is considered to be a hypoxanthine-guanine PRT activity (HGPRT, EC 2.4.2.8).

Hypoxanthine/guanine + PRPP $\rightarrow$ IMP/GMP + PPi

Once IMP is generated, the de novo pathway diverges towards synthesis of adenylate (AMP) and guanylate (GMP), processes that both require two enzymatic steps. Most parasites are capable of synthesizing AMP and GMP from IMP, and interconverting the three nucleoside monophosphates (Gero et al., 1990; Ullman et al., 1995).

A gene encoding the HGPRT protein has been cloned from P. falciparum (King et al., 1987; Vasanthakumar et al., 1991). The conserved regions in comparison with the human enzyme are clustered around the phosphoribosylpyrophosphate (PRPP) binding motif, i.e. the active site that would most likely be targeted by chemotherapeutics. The predominance of HGPRT in the purine salvage pathway indicates that HGPRT inhibitors might serve as effective therapeutic agents for the diseases treatment or prophylaxis. Comparative complement selections in bacteria have detected compounds, notably through modifications in the 6 position of purine base, with selective preference for parasitic HGPRT, and they could represent initial lead compounds (Eakin et al., 1995). The crystal structure of human HGPRT with bound GMP was recently solved by X-ray diffraction to a resolution of $2.5 \mathrm{~A}$ (Eads et al., 1994), but initial inspection of possible differences in the amino acids within the substrate-binding site of human and parasite HGPRT revealed no obvious differences (Eakin et al., 1995). However, current molecular models could resolve structure of the Plasmodium protein that could be exploited in the near future as part of a structure-based strategy to design novel antiparasitic drugs that target biochemical attributes of parasite HGPRT proteins. Nevertheless, although HGPRT has been an attractive candidate for inhibitor discovery and design, an essential nutritional function in purine salvage has not yet been definitively established for any parasite (Ullman \& Carter, 1995).

The metabolic capacity of HGPRT enzymes to trap membrane-permeable purine nucleobase analogues intracellularly as phosphorylated nucleotide products has stimulated considerable therapeutic interest, since analogues of naturally occurring purine bases, termed subversive substrates, can function as prodrugs and enter the nucleotide pool with lethal consequences. Indeed, only purine base analogues that would be selectively phosphoribosylated would be lethal, and substrate-specificity differences between parasites and host have been demonstrated (Queen et al., 1989). Alteration of the purine ring at the 6, 7 (sangivamycin, tubercidin) or 8 positions significantly increased the toxicity of the compound against P. falciparum in in vitro culture. The mechanisms of toxicity of deoxyadenosine and adenosine analogues, whose normal fate involves transport, metabolism and incorporation into nucleic acids appears to vary significantly between $P$. falciparum and mammalian cells (Coomber et al., 1994). Synthesis of novel cytotoxic nucleosides that exclusively penetrate into infected cells is of potential 
interest. However, it is worth mentioning K. Van Dyke's statement: "after having screened over 10,000 drugs for the United States Army, I have never found any antipurine or pyrimidine compound without significant host toxicity" (Van Dyke, 1990). However, the stereospecificity of the sugar moiety of the nucleoside required for its penetration into normal cells (Gati et al., 1990) underscores the theoretical potential of this approach.

\section{PYRIMIDINE BIOSYNTHESIS}

By contrast with the universal auxotrophy of purines, Plasmodium is unable to salvage pyrimidine bases or nucleosides and, as most other parasite protozoa, has to synthesize pyrimidines de novo, with maximal biosynthesis occurring during the transition from trophozoites to schizonts (Gero and O'Sullivan, 1990).

$$
\mathrm{HCO}_{3}^{-} \rightarrow \text { Carbamylphosphate }
$$

$\rightarrow$ N-carbamyl-L-aspartate $\rightarrow$ L-dihydroorotate

$\rightarrow$ Orotate $\rightarrow$ Orotidine 5'-phosphate $\rightarrow$ UMP

$$
\rightarrow \mathrm{UDP} \rightarrow \mathrm{UTP} \rightarrow \mathrm{CTP}
$$

By contrast, humans are able to synthesize pyrimidine nucleotides via the de novo or salvage pathways. Inhibitors of malarial de novo pyrimidine biosynthesis could thus be effective antimalarial drugs, as the patient could still synthesize UTP and CTP from uridine. For these reasons, pyrimidine antagonists have considerable potential as antimalarial drugs.

The first three enzymes of the pathway, carbamyl phosphate synthase (EC 6.3.5.5), aspartate transcarbamylase (EC 2.1.3.2) and dihydroorotase (EC 3.5.2.3) are separate proteins in Plasmodium, whereas in most eukaryotes they are linked on a trifunctional polypeptide, the CAD complex (Flores et al., 1994). The fourth enzyme, dihydroorotate deshydrogenase (DHOD, EC 1.3.3.1) catalyses oxidation of L-dihydrooroate to L-orotate in a single redox reaction, and is the only localized in the mitochondrial organelles (Krungkrai, 1995). The last two enzymes, orotate phosphoribosyltransferase (EC 2.4.2.10) and orotidylate (OMP) decarboxylase (EC 4.1.1.23), have also been described in P. falciparum (Gero \& O'Sullivan, 1990). It is remarkable that the inhibition of dihydroorotase by the dihydropyrimidine analogue, THDO, or of OMP decarboxylase by pyrazofurin, arrests growth of $P$. fal- ciparum but the rate of pyrimidine nucleotide biosynthesis after the blockage is still high. Moreover, only moderate decreases in intracellular UTP, CTP and dTTP are observed, suggesting that death of the parasite is not primarily due to a pyrimidine nucleotide deficiency (Seymour et al., 1994). Accumulation of toxic metabolites, or imbalance between the deoxynucleoside triphosphates, which could result in genetic miscoding, could explain the antimalarial effect. Note also that the substrate of the inhibited reaction may accumulate to a high enough concentration to compete with the drugs for binding to the enzyme, thus restoring the original flux through the metabolic pathway. Accumulation of N-carbamyl-L-aspartate due to inhibition of dihydroorotase may thus result in the development of metabolic resistance (Seymour et al., 1994). Substituted orotate derivatives significantly inhibit de novo biosynthesis of pyrimidine nucleotides (with major accumulation of 6-substituted triphosphate nucleotides), and inhibit both in vitro growth of $P$. falciparum ( $\mathrm{IC}_{50}$ in the nanomolar range) and in vivo development of P. yoelii (Krogstad et al., 1994; Seymour et al., 1994), with concentration range which suggests that inhibition of thymidilate synthetase could be responsible for the effect. Considering that the parasite lacks the ability to salvage preformed thymidine but not the mammalian cells, the combined use of the thymidilate synthase inhibitor and thymidine has been suggested (Rathod et al., 1994), but more effective and selective inhibitors of malarial thymidilate synthetase would still be needed. However, the recent report that rapid selection of 5-fluoroorotate-resistant $P$. falc $i$ parum occurs in the presence of a mutagen agent indicates that the in vivo use of 5-FO for malaria chemotherapy could be hazardous (Rathod et al., 1994).

\section{MITOCHONDRIAL INHIBITORS}

In Plasmodium, mitochondrial electron transport has a major role in providing dihydroorotate deshydrogenase (DHOD), a mitochondrial enzyme which is essential in de novo biosynthesis of pyrimidines. The enzyme catalyses a two-electron oxidation combined with the reduction of coenzyme $Q$ (ubiquinone, CoQ) to ubiquinol, and accounts for limited $\mathrm{O}_{2}$ utilization in the parasite (Krungkrai, 1995).

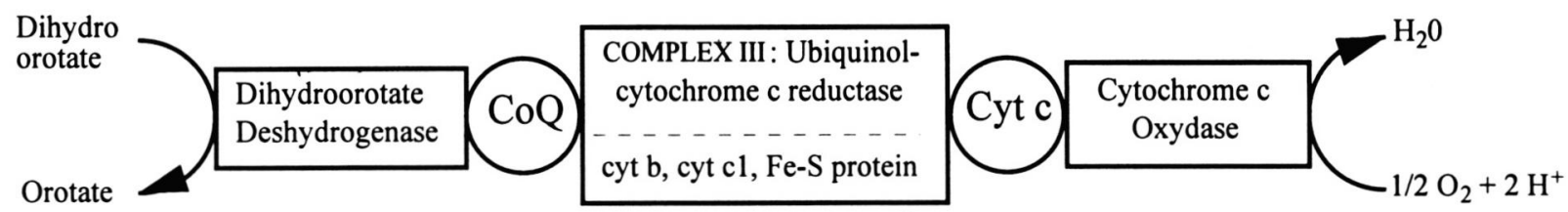

Fig. 1. - Coenzyme Q-mediated dihydroorotate deshydrogenase reaction in Plasmodium mitochondria. CoQ mediates the electron transfer from DHOD to cyt c, while the cytochrome c oxydase complex catalyses the electron transfer to molecular oxygen, the final step in electron transport. Coenzyme Q analogues such as atovaquone bind to the bc1 complex (complex III), inhibiting electron transport which is linked through dihydroorotate deshydrogenase to pyrimidine biosynthesis. 
CoQ or ubiquinones are widely distributed electron transport components that consist of a benzoquinone aromatic nucleus with four substituents. One of them is a polyprenyl tail, varying from 6 to 12 isoprene units, that confers the membrane localization through lipophilic properties; the length of this tail can be a means of characterizing different species. In mammalian cells, at the mitochondrial membrane, a large endogenous $\mathrm{CoQ}_{10}$ pool gathers electrons from various deshydrogenases and simultaneously directs proton movements until a proton gradient is established across the membrane which can be associated with ATP production. In Plasmodium, $\mathrm{CoQ}_{8}$ appears predominant but few studies on amounts, subcellular locations, and functions have been undertaken, and other CoQ homologues cannot be excluded. Moreover, very little is known about ubiquinone synthesis, but p-hydroxybenzoic acid could be the direct precursor of the aromatic ring, while the polyprenyl side chain of CoQ could be synthesized via the mevalonic acid pathway. The former is important since mammalian cells have lost this biosynthetic capability, and thus rely on dietary Tyr or Phe as a source of p-hydroxybenzoic acid (Ellis, 1994).

CoQ was subsequently recognised as a potential antimalarial target since numerous inhibitors, that are known to interfere with electron transport through the bc1 complex, possess antimalarial properties. This includes menadione, menoctone, 2-cyclohexyl-3hydroxynaptoquinone (58C80), atovaquone (566C80) and 8-aminoquinolines (antimalarial 8-aminoquinolines are proposed to be metabolized to products such as 5,6-quinoline diquinone, whose structures are similar to hydroxynaphtoquinones). Due to their structural similarities with reduced CoQ, these drugs block the respiratory chain of malarial mitochondria at complex III, inhibiting electron transfer to ubiquinone from dihydroorotate deshydrogenase.

The question of the specificity of parasite electron transport has been addressed through sequencing the $6 \mathrm{~kb}$ mitochondrial DNA of $P$. falciparum and the predicted structure of parasite electron transport. The overall structure of the three polypeptides, cytochrome c oxidase subunits 1 and 3, and cytochrome b (cyt b), are similar to those of other species. Cyt b is an integral membrane protein with 8 predicted membranespanning domains present in a multisubunit complex catalysing electron transport from CoQ to cyt c. This complex (called the bc1 complex) contains 4 redox centers: 2 hemes in cyt b, one heme in cyt $c 1$ and the iron-sulfur cluster of the Rieske Fe-S protein. The two distinct catalytic sites of cyt $b$ occur on each side of the inner mitochondrial membrane. $\mathrm{COQH} 2$ oxidation occurs at the cytoplasmic site (Qo site), whereas CoQ reduction occurs at the matrix site (Qi site). Analysis of the cyt b structure in P. falciparum showed that the critical quinone binding sites were quite divergent from those of human cyt b, and that these changes likely account for the resistance of the parasite cyt bc1 complex to antimycin and related inhibitors. The same features are responsible for the increased affinity of cyt b for hydroxynaphtoquinone derivatives, explaining the therapeutic value of these drugs (Vaidya et al., 1993). Using isolated malarial mitochondria, Fry and Pudney found that atovaquone forms a covalent adduct with a $11.5 \mathrm{kDa}$ protein probably from complex III. Atovaquone was able to inhibit (probably by binding at either the Qo or the Qi site) the bc1 complex of malarial parasites at 1,000-fold lower concentration than required for inhibiting rat mitochondria (Fry et al., 1992). The therapeutic index is probably enhanced by the ability of mammalian cells to use exogenous pyrimidines. The moderate in vitro inhibition of DHOD by atovaquone $(\mathrm{Ki}=27 \mu \mathrm{M})$ supports that inhibition of pyrimidine biosynthesis is indirect.

The inhibition of electron transfer at this site thus represents an important target for chemotherapeutic attack in parasitic protozoa. Alternative theories for the antimalarial effect involve the generation of free radicals during interaction of the drugs with the respiratory chain (see below). However, reversion of the atovaquone effect by orotic acid added to P. falciparum culture strongly corroborates the former mechanism (see Fowler et al., 1995).

The antimalarial atovaquone is highly effective in vitro against erythrocytic stages with $\mathrm{IC}_{50}$ of $1 \mathrm{nM}$, against the liver and mosquito stages, and in vivo against murine, simian and $P$. falciparum malaria. In contrast to previous members of the hydroxynaphtoquinone series, it is metabolically stable with an elimination halflife of $70 \mathrm{~h}$. Despite this promising profile, its monotherapeutic use has been compromised since phase II clinical trials using $500 \mathrm{mg}$ doses resulted in recrudescence rates of approximately $30 \%$, which has been attributed to the emergence of resistant parasites. However, as an inhibitor of electron transport, it has a novel mode of action and all drug-resistant strains of $P$. falciparum tested to date have been sensitive to atovaquone (Hudson, 1993). Combinations with other antimalarial drugs revealed antagonism with quinolines and artesunic acids. In contrast, combinations with tetracycline (antibiotics which are now commonly used against chloroquine-resistant strains and that interfere with mitochondrial/prokaryote-like protein synthesis (Gero \& O'Sullivan, 1990)) and proguanil were synergistic. Proguanil was selected as the preferred partner, and this combination is now being developed by the Wellcome Foundation. Hydroxynapthoquinone also has a broad spectrum of anti-protozoal activity, and atovaquone is currently licensed as an alternative agent for oral use in the treatment of mild to moderate 
Pneumocystis carinii pneumonia and toxoplasmoris, opportunistic infections common in AIDS patients (Spencer et al., 1995).

\section{FOLATE METABOLISM}

The synthesis of thymidine nucleotides is intimately linked to folate metabolism (Gero \& O'Sullivan, 1990), and pyrimidine biosynthesis can also be inhibited by folate-based inhibitors. Recent reports indicate that Plasmodium can supply its own p-aminobenzoic acid (PABA) needs through either de novo synthesis or salvage pathways (McConkey et al., 1994). Plasmodia also have both dihydropteroate synthetase (DHPS; EC. 2.5.1.15) and 6-hydroxymethyl-7,8-dihydropterin pyrophosphokinase (PPPK; EC 2.7.6.3) which catalyse the reaction in folic acid synthesis before DHPS. Both enzymes were recently, and concomitantly, found in gene sequence analyses to be a bifunctional protein in P. falciparum, thus corroborating their copurification (Brooks et al., 1994; Triglia et al., 1994). The PPPK-DHPS protein is a very attractive target for antimalarial as neither of these two enzyme activities are present within the human host of the parasite, and identification and analysis of this gene are the first steps in the process of finding highly selective inhibitors. Dihydrofolate reductase (DHFR, EC 1.5.1.3) catalyses NADPH-dependent reduction of dihydrofolate (DHF) to tetrahydrofolate (THF) and exists as a bifunctional enzyme with thymidylate synthetase (TS, EC 2.1.1.45) with a 94 amino acid bridging sequence whereas TS and DHFR are separate entities in most eukaryotes. The conversion of PABA to folate is a principal target for antimalarial drugs, including potent sulfonamides which are chemical analogues of PABA and pyrimethamine and cycloguanil that inhibit the DHFR -TS, an essential enzyme for converting DHF to THF. Sulphurbased antimalarial drugs targeted at DHPS are frequently used in synergistic combinations with DHFR inhibitors to combat chloroquine-resistant malaria. The molecular basis of the therapeutic activities of these compounds lies in the structural difference between malarial and mammalian DHFR, the parasite enzyme being 1,000-fold more susceptible than the mammalian counterpart to pyrimethamine and cycloguanil. The antimalarial pyrimethamine binds to dihydrofolate reductase from $P$. falciparum with a $\mathrm{K}_{\text {diss }}$ of $10^{-10} \mathrm{M}$. While the ability of malarial parasites to develop resistance to these compounds was recognised decades ago, the molecular basis of the resistance against the drugs was only recently understood. Biochemical and genetic evidence strongly suggests that the major mechanism of DHFR-inhibitor resistance in $P$. falciparum is the altered binding affinity to the drugs caused by single point mutations that structurally change the enzyme (Cowman et al., 1990; Wellems,
1991). P. falciparum lines resistant to the most commonly used sulpha-drug sulfadoxine, also carry point mutations in five positions of the DHPS coding region (Brooks et al., 1994; Wang et al., 1995), but it is not yet fully clear how this specific change affects the resistance phenotype.

With improved knowledge of the active site of $P$. falciparum DHFR, and the specificity of point mutations involved in resistance, it would now be logical to look for alternative antifolates that could combat both resistances. Probing the molecular structure of ligand and inhibitor binding sites may come up with some rational chemical modifications of the drugs to make them efficient against the different mutations. The combination of these new drugs may ultimately circumvent all resistance-conferring mutations. Physicochemical and threedimensional characterization of the DHFR-TS molecule would stimulate the development of new antifolateinhibitors. The P. falciparum DHFR enzyme has been produced using an artificial DHFR gene that possesses characteristic E. coli codons, to produce the desired amino acid sequence of the parasite DHFR. It can now be used for structural analysis and testing candidate DHFR inhibitors in vitro (Sirawaraporn et al., 1993; Sano et al., 1994). Currently used antifolate combinations include molecules such as sulfadoxine/pyrimethamine and sulfalene/pyrimethamine, which have long elimination half lives, of 60 and to more than $100 \mathrm{~h}$. This has the advantages of allowing seric levels at efficient concentrations for long periods of time, but it also has disadvantages, e.g. adverse reactions and resistance induction. New short half-life antifolates are required to avoid the rapid appearance of resistance. Combinations using short half-life sulfonamides and sulfones, are therefore being studied. These include biguanides and triazines, the mechanisms of resistance appear to differ from those of pyrimethamine. The combination of biguanide chlorproguanil with dapsone appears to have potential for non-severe falciparum malaria (Olliaro \& Trigg, 1995).

\section{GLUCOSE UTILISATION}

T n P. falciparum-infected erythrocytes, glucose utilization is as much as 100-times the rate observed in uninfected erythrocytes. Plasmodial acristate mitochondria do not possess a functional Kreb's cycle, and lactate, which is produced from pyruvate, is the end product of glucose degradation. Most glycolytic enzymes have been observed in Plasmodium, and some of their properties differ from those of corresponding host enzymes (Roth, 1990). Numerous sequences have already been reported, but vulnerability of the parasite to compounds that interfere with 
glycolysis remains to be proven. Lactate deshydrogenase represents a potential antimalarial target because of its distinctive properties as compared to human $\mathrm{LDH}$, and the presence of a 5 amino acid insertion at the site that makes contact with pyruvate (Bzik et al., 1993).

\section{LIPID METABOLISM}

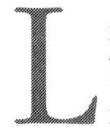

ipids are major constituents of biological membranes. The lipid content of infected erythrocytes is considerably higher than that of normal erythrocytes, since it has three concentric membranes: the host cell, parasitophorous vacuole and cellular membranes, and many membrane-bound intraparasitic organelles. The membrane biogenesis accompanying parasite growth requires parasite-driven lipid synthesis because the erythrocyte lacks this capacity. Abundant phospholipid (PL) biosynthesis occurs during the intraerythrocytic phase, which the parasite manages through a variety of complex metabolic pathways. However, the intracellular parasite depends on the host for supplies of polar head groups and fatty acid molecules that it cannot synthesize. As such, plasma fatty acids and lysophospholipids are both sources of fatty acids, and carrier-mediated importation of choline is increased significantly. Cholesterol does not have a structural role in malaria, and the role of exogenous lipoproteins in malaria PL production is uncertain, but lipoproteins have not been shown to be essential in this process. The parasite can synthesise phosphatidylcholine (PC) and phosphatidylethanolamine (PE) de novo. It can also produce PE by decarboxylation of phosphatidylserine (PS), and PC by methylation of PE (Holz, 1977; Vial et al., 1990; Vial and Ancelin, 1992).

This knowledge has led to a novel antimalarial pharmacological approach that involves analogues of polar head groups acting by substitution (Vial et al., 1984), competition (Ancelin et al., 1985; Ancelin et al., 1986), or with unnatural fatty acids (Beaumelle et al., 1988). The most promising results were obtained with blockers of choline transport, probably mediated by the native (though altered) carrier of the erythrocyte membrane. This target is easily accessible from the extracellular space, and constitutes the rate-limiting step in the provision of choline to the parasite for PC synthesis (Ancelin et al., 1989). Choline transport is effected by a diffusion system involving a cyclic and asymmetric transporter. Transacceleration experiments using imidazole or ethanolamine showed that reorientation of the empty transporter is the rate limiting step. Like several other native carriers, its action is modified upon infection, leaving its affinity for choline identical, but increasing its maximal velocity (Vmax) 10-fold as compared to the non-perturbed carrier (Ancelin et al., 1991).

More than 350 compounds, synthesized by two groups of chemists, revealed that interfering with the polar head transport is lethal to the parasite. The trophozoite stage (i.e. the most intense phase of PL biosynthesis activity during the parasite cycle) was found to be by far the most sensitive stage to the drug as it had a lower $\mathrm{IC}_{50}$ and a full antimalarial effect after 4-hour contact with the drug at low concentrations. The compounds are also effective in vitro against strains or isolates resistant to current antimalarials, highlighting their importance in the framework of multidrug resistance.

Development of the pharmacological model has now been fully validated with the malaria-infected mouse with a therapeutic index of less than 40 , and success in inhibiting parasitemia by as much as $15 \%$. Intramuscular administration of one lead compound in Aotus lemurinus monkey infected with the virulent chloroquine-resistant FVO P. falciparum isolate, succeeded in curing parasitemia without recrudescence, and the therapeutic index seemed to be higher than 50. As all of the most effective (nanomolar) compounds contains quaternary amines, and as this structural aspect limits oral bioavailability, this structural feature is currently being changed without loss of biological effect, and attempts are under way to reduce toxicity and improve oral absorption. Newer compounds possess potent antimalarial activity in vitro against $P$. falciparum (with $\mathrm{IC}_{50} \mathrm{~s}$ in the nanomolar range), are better tolerated and far better absorbed than the former series. They also possess in vivo antimalarial activity in the murine model with an improved therapeutic index. Their activity against $P$. falciparum in monkey has not yet been evaluated. Pharmacokinetic characteristics determined in the mouse, dog and monkey after intramuscular or oral administration revealed elimination half-lives of 7-24 h.

Hence, blocking development of the parasite using drugs which selectively interfere with PL metabolism is a quite realistic approach, and the in vivo antimalarial activity that is exerted in monkeys without recrudescence makes it very promising. Although there is no indication of potential resistance to date, a potential problem of using a parasite biochemical pathway as a drug target is that many parasites are able to use alternative biochemical pathways, thus conferring resistance and rendering the drug ineffective. In terms of choline transport and inhibition of PC biosynthesis as a drug target, we noted that the alternative pathway of PC synthesis from PS does not compensate for the decrease in synthesis caused by choline transporter blockers. Nevertheless, we are aware of the fact that the role of "transporter blockers" in specifically affecting parasite viability could be questioned, since most 
of the compounds were assessed in terms of PC synthesis, not in terms of their direct action on choline transport. Isolation, characterization and identification of the target by gene sequencing would now be an attractive approach.

\section{PROTEASES AND HAEMOGLOBIN DEGRADATION IN PLASMODIA}

$\mathrm{P}$ roteolytic enzymes or proteases are a diverse group involved in many physiologic and pathologic processes and are found throughout the plant and animal kingdoms. Many different types of proteases are frequently expressed at different stages of the parasite cycle (Schrevel et al., 1990). Malarial proteases are likely required during erythrocyte invasion by the merozoites and erythrocyte rupture of mature schizonts. During both events, the erythrocyte cytoskeleton serves as an important barrier to malarial parasites, in addition to the erythrocytic plasma membrane. Several proteases, released from the rhoptry and microneme during erythrocyte invasion and rupture, should thus be able to digest erythrocyte surface proteins associated with the cytosleleton or directly degrade cytoskeletal proteins. Moreover, many mature schizont and merozoite proteins are proteolytically processed immediately before or during erythrocyte rupture and invasion, suggesting that proteolytic fragments have roles in these processes. Available evidence suggests roles for both serine and cysteine proteases, and both process are blocked by serine protease inhibitors (reviewed in Schrevel et al., 1990; Breton et al., 1993; McKerrow et al., 1993; Holder et al., 1994). As an example, a $76-\mathrm{kDa}$ serine protease is bound in an inactive form to P. falciparum schizont and merozoite membranes by a glycosyl-phosphatidylinositol anchor and is likely activated by a phosphatidylinositol-specific phospholipase $\mathrm{C}$ during the merozoite stage to cleave the erythrocytic protein band 3. Synthetic peptides derived from enzyme cleavage sites within erythrocyte band 3 are able to inhibit band 3 degradation and in vivo erythrocyte invasion (Breton et al., 1992; Breton \& Peirera da Silva, 1993, and personal communication). In the same way, a serine-rich $P$. falciparum schizont antigen (named SERA or SERP or p126) identified on parasitophorous vacuoles of schizonts, could possess protease activity and have potential roles in proteolysis of erythrocyte cytoskeletal or parasite proteins (Delplace et al., 1986; McKerrow et al., 1993).

The intraerythrocytic malaria parasite $P$. falciparum internalises and degrades $25-75 \%$ of the host's haemoglobin $(\mathrm{Hb})$ during a short part of its intraerythrocytic development. Hb degradation takes place in acidic food vacuoles where the heme component of $\mathrm{Hb}$ is processed in malarial pigment and globin is hydrolysed into free amino acids. Globin degradation involves multiple enzymes, including at least three aspartic proteases (Gluzman et al., 1994) and one cysteine protease (now termed falcipain) (Goldberg, 1992; Rosenthal et al., 1992). The gene for an aspartic haemoglobinase has been cloned and encodes a protein with $35 \%$ homology to human renin and cathepsin $\mathrm{D}$, although it has an unusually long propiece with potential membrane spanning regions (Francis et al., 1994; Gluzman et al., 1994). The P. falciparum (Rosenthal \& Nelson, 1992) and P. vivax (Rosenthal et al., 1994) cysteine proteases named falcipain have recently been cloned. The first critical step in $\mathrm{Hb}$ degradation was assumed to be cleavage of the $\alpha$ chain by an aspartic protease between residues phe 33 and leu 34; this cleavage site is retained in all known vertebrate $\mathrm{Hb}$ (Goldberg, 1992; McKerrow et al., 1993; Rosenthal, 1995). However, cystein protease inhibitors completely block globin hydrolysis in intact parasites (Rosenthal, 1995), and falcipain can also cleave native $\mathrm{Hb}$ (Salas et al., 1995), suggesting that a trophozoite cysteine proteinase is required for initial cleavage of globin and that the efficiency of globin hydrolysis is likely augmented by the interaction of multiple enzymes. Various exopeptidases finish the proteolysis process, generating free amino acid for the parasite's nutrition.

In any case, $\mathrm{Hb}$ degradation is an ordered process that may help in designing specific inhibitors that would be crucial for parasite growth. Cysteine protease inhibitors (Rosenthal et al., 1991) and aspartic protease inhibitors (Gluzman et al., 1994) block P. falciparum development, both inhibitors acting synergistically (McKerrow et al., 1993; Gluzman et al., 1994). E-64, a cysteine protease inhibitor, appeared to act primarily on trophozoites and pepstatin, an aspartic protease inhibitor, primarily on rings and schizonts (Bailly et al., 1992). Many peptides fluoromethyl ketone inhibitors inhibit in vitro growth of $P$. falciparum. Their actions are correlated with the degree of inhibition of cysteine proteases and the accumulation of non-degraded globin inside the food vacuole (Rosenthal et al., 1991; Rosenthal, 1995). In vivo treatment of P. vinckeiinfected mice with $\alpha$ fluoromethylketone-containing inhibitor of this cystein proteinase resulted in long-term cure in $80 \%$ of mice (Rosenthal et al., 1993).

Many aspects concerning localization, substrate specificity, functional roles, as well as essentiality for plasmodial growth, have not yet been clarified, and specific inhibitors for in vivo use still have to be designed. However, proteases of the malarial parasite should soon provide promising targets for antimalarial chemotherapy. Indeed, the substrate specificities of pro- 
teases of infectious organisms are unique and differ from those of human proteases (Roose et al., 1995). They are particularly amenable to homology modelling since many crystallographic structures have been determined and can be accessed through the Brookhaven Protein Databank. This is specially true for the serine and cysteine proteases. The vacuolar cysteine proteases of P. falciparum (Rosenthal \& Nelson, 1992) were modelled and compounds selected in terms of their active sites and substrate binding sites (Sun \& Cohen, 1993). In order to identify nonpeptide inhibitors, a key feature of protease catalysis is their ability to bind the so-called transition state, a structural intermediate in the pathway to peptide-bond cleavage. A pragmatic corollary of the transition-state theory is that development of protease inhibitors as pharmaceuticals has often required designing of inhibitors to mimic its transition state. Overall, proteases should be excellent direct targets. More selectivity is needed to avoid host toxicity. Substrate preferences of these enzymes differ from those of homologous host enzymes, so selectivity should be possible. The way is clear to develop a new class of antimalarials that interfere with these essential catabolic pathways.

\section{HAEM POLYMERIZATION}

Digestion of up to $80 \%$ of host cell $\mathrm{Hb}$ within the parasitic vacuole is associated with the release of potentially toxic haem (Fe (II) protohaematoporphyrin) which is sequestered into an insoluble pigment called haemozoin, consisting of polymerized $\mathrm{Fe}(\mathrm{III})$ protohaematoporphyrin subunits. The haem polymerization process was previously reported to be enzymemediated and the target of the quinoline antimalarial drugs chloroquine and quinine (Slater et al., 1992). It can also occur as a chemical process, dependent only on the presence of haem-derived material associated with haemozoin and not on proteins (Dorn et al., 1995). However, this discovery did not invalidate haem polymerization as a target for drug intervention but the mechanism by which haemozoin formation is initiated and the mechanism of chloroquine action remains unresolved. Another possibility, among a dozen of others (Schlesinger et al., 1988; Pussard et al., 1994), might concern the heme that accumulates during chloroquine action, either by direct chloroquine sequestration or heme polymerase inhibition. The hemechloroquine complex might damage membranes as well as aspartic proteases or the vacuolar cysteine protease (Gluzman et al., 1994). The chloroquine target has long been validated, and its identification and characterization are still problems that have to be overcome since they would allow attack of this exceptionally essential target at novel sites with new series of drugs.

\section{NEW PERMEABILITY PATHWAYS; INTERFERENCE WITH THE HOST CELL MEMBRANE}

A $s$ the intraerythrocytic parasite matures, major modifications occur in host cell membrane: the lipid composition is altered, probably explaining the increased fluidity; native proteins are modified and new proteins of parasite origin associate with it either peripherally or intrinsically; as a result of these changes, deformability of the infected cell is reduced, and the rate of PL flip-flop increases (Vial \& Ancelin, 1992). These changes have attracted much attention because of their possible involvement in the pathophysiology of the disease, such as cytoadherence, rosette formation, thrombosis, anaemia and phagocytosis, and also since they are supposed to underlie the physiological changes that permit intracellular growth of the parasite.

Investigating transport through red cell and parasite membranes has provided evidence on the permeation of low molecular weight solutes (cations and anions, amino acids and sugars) through common pathways since inhibitors of anion transport blocked entry of all of these solutes into the cells (Cabantchik, 1989). The pathway is anion selective and non-saturable and therefore quite unlikely possess characteristics of a conventional transporters. Besides, in 1991 original studies reporting the existence of a parasite-induced parasitophorous duct (or tubovesicular system) in $P$. falciparum-infected erythrocytes that permitted access of serum macromolecules to the parasitophorous vacuole have met with considerable scepticism. This connecting duct that was characterized as being $70 \mathrm{~nm}$ diameter, would open new possibilities for novel anti-chemotherapeutic tools. However, many other experiments have found no evidence for the passage of material through a duct system. Details of these modified properties have been recently and comprehensively discussed in detail (Gero et al., 1994; Elford et al., 1995). Conceptually, blockage of new permeability pathways, or use of cytotoxic agents that would only permeate erythrocytes after infection, have been formulated. This drug targeting tactic has also been experimentally demonstrated with phloridzin and its analogues (Silphen et al., 1988), the zinc chelator dipicolininic acid (Ginsburg et al., 1986) that readily permeate infected erythrocytes, and also concern gramicidin inhibition of parasite growth (unpublished results and (Moll et al., 1991)). Examples also include inhibition of choline transport and use of lipophilic iron chelators (see below). Another potential tactic would be co-administration of a cytotoxic nucleoside (tubercidine or sangivamycin) and NBPMR. This combination would 
inhibit entry of the cytotoxin tubercidin into normal cells, while its influx into infected cells by means of new permeability pathways would proceed unhampered. This approach assumes that all host cells are equally and efficiently protected by the transport inhibitor against the cytotoxic nucleoside, but it disregards the potential deleterious effects of curbing adenosine detoxification. Testing this tactic in vivo in $P$. berghei or $P$. yoelii malarias, resulted in reduction of parasitemia but not in radical cure (Gero et al., 1992; Gero, 1994 \#606).

\section{OXIDATIVE STRESS}

\section{AS A CHEMOTHERAPEUTIC STRATEGY}

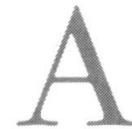

minor part of oxygen (estimated at $5 \%$ ) consumed by a human is converted by side reactions into reactive oxygen species such as $\mathrm{O}_{2}^{\bullet-}, \mathrm{HO}_{2}{ }^{\bullet} \mathrm{ONOO}^{-}$(peroxynitrite anion), $\mathrm{HO}^{\bullet}$ and $\mathrm{H}_{2} \mathrm{O}_{2}$. This oxydative stress is a consequence of aerobic life and is important in the organism's chemical defence against invaders. NADPH oxydase of activated leukocytes and macrophages thus produce superoxyde anions $\left(\mathrm{O}_{2}{ }^{-}\right)$which serve as starting material for the synthesis of chemical agents, notably the highly toxic $\mathrm{OH}^{\bullet}$ radicals that combat bacteria, parasites and tumour cells.

Erythrocytes contain high concentrations of polyunsaturated fatty acids, molecular oxygen and ferrous ions in the ligand state. It might therefore be highly vulnerable to the main potential hazards of aerobic environments, i.e. formation of reactive oxidative species (ROS). Autooxydation of oxyhemoglobin (Hb) to methaemoglobin (Met-Hb) constitutes a continual spontaneous source of ROS with generation of superoxyde radicals since about $3 \%$ of the total body $\mathrm{Hb}$ is converted to Met-Hb each day, even under physiological conditions. These reactions are accelerated by high ionic strength and low $\mathrm{pH}$. The Met-Hb produced is rapidly reduced again by Met- $\mathrm{Hb}$ reductase, which is linked, through its requirement for NADH, to the glycolytic pathway. Another source of radicals in ery-

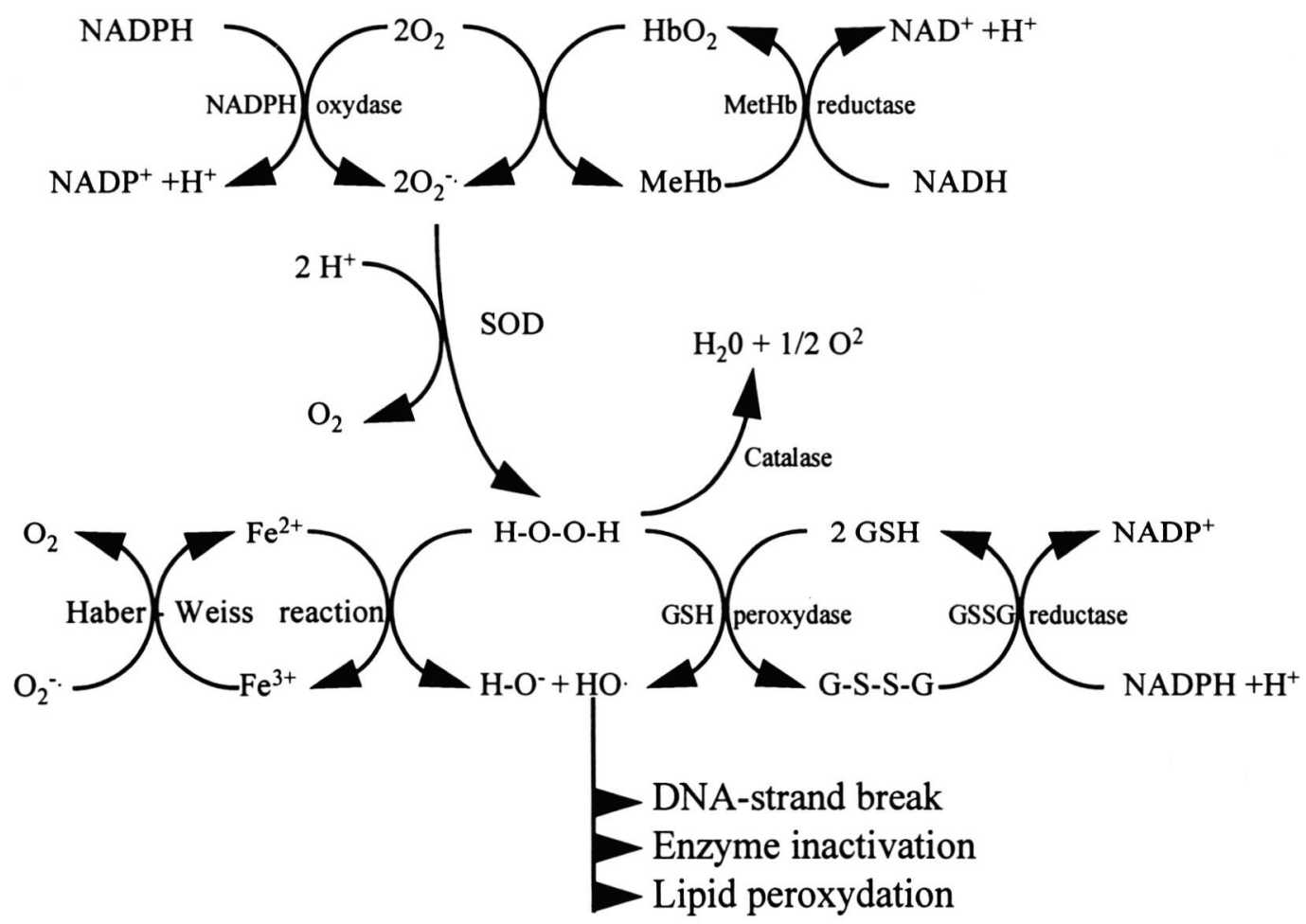

Fig 2. - Redox cycling in animal cells and malarial infected erythrocytes. $\mathrm{O}^{\bullet-}$ and $\mathrm{H}_{2} \mathrm{O}_{2}$ are much less reactive than $\mathrm{HO}{ }^{\bullet}$, the former does not easily cross the biological membrane while $\mathrm{H}_{2} \mathrm{O}_{2}$ does. Hydroxyl radical is highly reactive with a great variety of organic molecules, but its effective diffusion is extremely low, indicating that the location of the hydroxy-radical generating system is critical; such production is likely harmful within or adjacent to membranes but relatively harmless in cytoplasm. Note that $\mathrm{H}_{2} \mathrm{O}_{2}$ produced by dismutation of $\mathrm{O}^{*}$ can react with intact $\mathrm{Hb}$ or MetHb, or with heme released during proteolysis, to liberate iron from the porphyrin ring. This reaction is accelerated by low $\mathrm{pH}$. Iron is required for oxygen activation to initiate lipid hydroperoxyde formation and is likely a true promoter of hydroxyl radical generation and contributes to peroxydation in Hb-containing systems. Hb may thus act as an iron supplying agent but not as a promoter of erythrocyte lipid peroxydation per se. These compounds are cytotoxic because of their ability to modify nucleic acids, thiol-containing proteins, and membrane lipids (Clemens \& Waller, 1987; Hunt \& Stocker, 1990). 
throcytes is the interaction of $\mathrm{Hb}$ with redox drugs or xenobiotics (Clemens et al., 1987; Hunt et al., 1990).

\section{PROTECTIVE MECHANISMS AGAINST OXIDATIVE STRESS}

Mechanisms for the detoxification of ROS are located in the cytoplasm and include the glutathion (GSH) peroxydase cycle and two other antioxydative enzymes, namely superoxyde dismutase (SOD; EC 1.15.1.1) and catalase (EC 1.11.1.6). Antioxidants such as vitamin C and $\mathrm{E}$ also protect natural molecules from oxidation or lead to the destruction of oxidised molecules.

Spontaneous dismutation of superoxyde radicals is greatly accelerated by SOD. The resulting hydrogen peroxyde is eliminated by GSH peroxydase, although there is a potential reserve mechanism in the form of catalase and other GSH-dependent mechanisms. GSH peroxydase is specific to GSH as a substrate but catalyses the decomposition of a range of peroxydes in addition to hydrogen peroxide (including oxygen, carbon, nitrogen, and sulfur based radicals). In each case, the peroxydes are reduced to alcohols. Interestingly, GSH peroxydase deficiency appears to be entirely benign. The tripeptide GSH is the main non-enzymatic intracellular antioxydant. It is kept in the reduced state by the flavoenzyme GSH reductase. GSH-based cellular functions include redox homeostasis, formation of deoxyribonucleotides, xenobiotic detoxification and amino acid transport. NADPH is the ultimate electron donor for decomposition of hydroperoxides by GSH and GSH reductase system. In mature erythrocytes, the only known mechanism for NADPH regeneration from NADP depends on oxidation of glucose via the hexose monophosphate shunt (HMPS). Glucose-6-phosphate deshydrogenase deficiency is typical example of hereditary sensitivity to haemolytic anaemia induced by oxidant drugs. The presence of antioxydants in cell membranes is a further defence against oxidation; the most important is probably vitamin $\mathrm{E}$, which appears to be a critical membrane protectant by interrupting the chain reaction which would lead to further lipid peroxydation. The vitamin $\mathrm{E}$ radical can be reduced to vitamin $\mathrm{E}$ by ascorbate. Lastly, in addition to intracellular antioxidant protection, cells and tissues are protected against oxidising free radicals by a complexity of extracellular antioxydant mechanisms, via e.g. components capable of immobilising a metal catalyst such as iron (Clemens \& Waller, 1987; Hunt \& Stocker, 1990).

\section{REDOX PROCESS IN MALARIAL-INFECTED ERYTHROCYTES}

Malarial-infected erythrocytes are demonstrably under oxidative stress (Vennerstrom et al., 1988; Golenser et al., 1989; Hunt \& Stocker, 1990; Ginsburg et al., 1994). Many procedures have been developed to determine enzymatic levels and oxidant stress-related metabolites in malaria-infected erythrocytes, and the scenario in $P$. falciparum-infected erythrocytes seems to substantially differ from that of normal cells.

Overall, ROS could be produced in the parasite's food vacuole, due to the acidic $\mathrm{pH}$, during the digestion of host cell cytosol (Atamna et al., 1993). In the presence of $\mathrm{H}_{2} \mathrm{O}_{2}$ and iron which is liberated from acidified $\mathrm{Hb}$ (Gabay et al., 1994), OH radicals can be produced by a Haber-Weiss reaction. Plasmodia succeed in accumulating ROS as attested by the increased level of met$\mathrm{Hb}$ and lipid peroxydes (Nakornchai et al., 1992; Simoes et al., 1992). The parasite itself is equipped with the same antioxidant defence systems as its host cell. $P$. falciparum is known to contain both an adopted host cyanide-sensitive SOD and an endogenous cyanide-resistant hydrogen peroxyde-resistant SOD (Fairfield et al., 1988; Ranz et al., 1989). Recent enzyme characterization (Becuwe et al., 1993) and cloning (D. Dive, personal communication) have revealed the presence of a parasite-biosynthesized, iron-dependent SOD. The cytosolic Fe-based-SOD of protozoan parasites differs both structurally and in terms of their inhibitor profiles from cytosolic SOD of their vertebrate hosts (Fairfield et al., 1988; James, 1994), and as such can be proposed as potential chemotherapeutic targets. Both $P$. berghei and $P$. falciparum contain elevated levels of GSH-peroxidase. The HMPS activity of $P$. falciparum infected erythrocyte is some 100 -fold higher than in normal erythrocytes. Most of this activity is due to parasite HMPS, although the host cell HMPS is also activated (Atamna et al., 1994). Nevertheless, both host and parasite defence mechanisms may be insufficient to deal with all the ROS generated by the parasite, since infected erythrocytes display considerable lipid peroxidation and are extensively phagocytosed by a mechanism akin to that observed in oxidatively stressed erythrocytes (Turrini et al., 1992).

\section{OXIDATIVE STRESS AS AN ANTIMALARIAL STRATEGY}

Survival of both parasites and erythrocytes depends on the delicate balance between oxydant stress and defence mechanisms. Many pharmacologically and toxicologically active compounds exert their effects by creating an oxydative stress either by creating ROS or neutralising the antioxidant systems. In the former case, an unfavourable balance can result from enhanced sensitivity of the host cell toward oxidative stress, or because of an additional stress induced by the parasite or from external sources such as food constituents, drugs, or from the immune response. Interfering with this balance would affect successful development of the parasite. This balance is conti- 
nuously changing and the parasite must cope with increasing oxidant stress and the decline of its protective capacity.

Inherited or acquired conditions, which predispose erythrocytes to oxidative stress, offer partial protection against $P$. falciparum infections. Clinical and epidemiological studies have provided further evidence that oxydative stress is an important mechanism for the destruction of parasites and tumour cells. The best known example is glucose-6-phosphate deshydrogenase (G6PDH) deficiency whose functional defect involves limited availability of NADPH through the hexosemonophosphate pathways, leading to an impairment of the GSH redox system, with a consequent marked increase in oxydative stress. Favism, which is characterized by episodes of haemolytic anaemia, also afford protection against malaria, and synergizes in the protection with G6PDH deficiency. The antimalarial principles of the fava bean that cause favism includes isouramil and divicine which act as redox cyclers (see below). Note that pro-oxidant drug administration stimulates ROS generation, which may overwhelm protective mechanisms. This is particularly likely when erythrocytes defences are already defective due to hereditary enzyme deficiency. In the case of drugs such as primaquine, the dose required to produce hemolysis of normal red cells is very much higher than that required to produce haemolysis in enzyme-deficient cells (Hunt \& Stocker, 1990; Beutler, 1994; Ginsburg \& Atamna, 1994; Martin, 1994).

\section{ANTIMALARIAL EFFECTS OF PROOXIDANTS}

Compounds can directly produce ROS or produce ROS according to so-called redox cycling. The use of direct oxidants (peroxides) was proposed after the observation that numerous peroxides, including $\mathrm{H}_{2} \mathrm{O}_{2}$, have antimalarial properties in vitro (at $\mu \mathrm{M}$ concentrations) and in vivo. The effect is suppressed in presence of catalase, implicating $\mathrm{H}_{2} \mathrm{O}_{2}$ as the causative agent. The lipophilic tert-butyl hydroperoxide which cannot be reduced by catalase, has an $\mathrm{IC}_{50}$ of $10 \mu \mathrm{M}$ and cures $P$. vinckei infection in mice. This agent also provokes hemolysis, which could be due to accelerated oxidative denaturation of haemoglobin, and lipid peroxidation associated with decreased GSH. Endoperoxide-containing compounds, such as epidioxy- $\Delta^{7}$ octalin, may also act through the production of oxidative stress (Buffinton et al., 1986; Vennerstrom \& Eaton, 1988).

Artemisinin (Qinghaosu) is an effective and promising antimalarial agent that was isolated from Artemisia annua, used in an ancient Chinese herbal remedy. Artemisinin derivatives are widely used since they are one of the few effective treatments for multi-drug resistant $P$. falciparum malaria. Artemisinin, which is not very soluble in any solvent, has stimulated the synthesis of more soluble derivatives. Dihydroartemisinin has been obtained, and etherified or esterified to produce derivatives with improved antimalarial activity, i.e. artemether, arteether, and artesunate. Oral formulations of artemisinin, artemether, artesunate and more recently of dihydroartemisinin are produced in China and in several developing countries. An injectable formulation of artemether, supported by Rhone Poulenc Rorer, the World Health Organization (WHO), along with a pharmaceutical production unit in China, should be registered shortly, while the development of arteether is currently in phase II trials under the auspices of WHO/Walter Reed Institute of Research (WRAIR) and the Dutch Company, ACF. There is ongoing research to synthesize more soluble, stable and effective derivatives. Artelinic acid, developed by Walter Reed, is currently in phase I trials with human volunteers. Artemisinin has stimulated synthesis of compounds, that also potentially induce oxidative stress. Only arteflene has so far reached human phase II clinical trials but development of this drug has been discontinued because of high recrudescence rates (Hien et al., 1993; Posner et al., 1994; Woerdenbag et al., 1994).

Understanding the mechanism of action of these new antimalarials may aid in the development of better second generation drugs. They are unique molecules because they contain an endoperoxide group which is involved in their antimalarial activity, probably by producing free radicals that damage the parasite membranes. Indeed, artemisinin produces activated oxygen species and lipid peroxydation in vitro (Scott et al., 1989). In addition, oxydant drugs potentiate the effects of artemisinin, while antioxidants such as catalase, DTT, and $\alpha$-tocopherol antagonise artemisininmediated antimalarial action (Krungkrai et al., 1987). Free radical formation is iron-dependent and iron chelators, such as DFO, inhibit artemisinin-mediated action (Kamchonwongpaisan et al., 1992; Meshnick et al., 1993). Hemin might play a role in the antimalarial action since hemin catalyses artemisinin decomposition (Zhang et al., 1992; Muhia et al., 1994) and may interact with artemisinin to cause oxidation of protein thiols (Meshnick et al., 1991; Wei et al., 1994). Artemisinin and derivatives possibly have a two-step mechanism of action. First, the drug interacts with intraparasitic heme, which catalyses its conversion into a free radical through opening of the drugs's endoperoxyde bridge. The free radical form of the drug then alkylates critical malarial proteins (Asawamahasakda et al., 1994; Meshnick, 1994; Yang et al., 1994). This would explain why the drug is selectively toxic to the parasite, since the parasites are rich in heme and 
heme catalyses the reductive decomposition of the endoperoxide bridge.

Several compounds X catalyse the one-electron reduction of $\mathrm{O}_{2}$ to $\mathrm{O}_{2}^{-\bullet}$ through redox cycling, sometimes dependent on the presence of reducing equivalents like $\mathrm{NAD}(\mathrm{P}) \mathrm{H}$.

$$
\begin{gathered}
\mathrm{NADPH}+2 \mathrm{X} \rightarrow 2 \mathrm{X}^{\bullet}+\mathrm{NADP}^{+}+\mathrm{H}^{+} \\
\text {and } 2 \mathrm{X}^{-}+2 \mathrm{O}_{2} \rightarrow 2 \mathrm{X}+2 \mathrm{O}_{2}^{-}
\end{gathered}
$$

This category includes naphtoquinones, menadione, menoctone and atovaquone (already mentioned as an inhibitor of DHOD) and compounds with a catechol nucleus such as quercetin, RC-12 and gossypol, or a pyrimidine nucleus, such as divicine and isouramyl. (Vennerstrom \& Eaton, 1988; Schirmer et al., 1995).

\section{GLUTATHIONE SYSTEM INHIBITORS}

The main defence against ROS is the GSH redox cycle, which involves the enzymes GSH reductase and GSH peroxydase. The former catalyse GSH disulphide (GSSG, oxidised glutathion) reduction to GSH at the expense of flavonucleotide NADPH. GSH is essential for avoiding oxidant stress, and the GSH redox cycle is a major defence system for the detoxification of ROS by reacting with $\mathrm{H}_{2} \mathrm{O}_{2}$ and organic peroxydes. The reduced GSH serves as a sulfhydryl buffer that maintains the cystein residues of $\mathrm{Hb}$ and other red blood cell proteins in the reduced state. The ratio of the intracellular concentration of GSH to that of GSSG is maintained at greater than 200. GSH takes part in many biological functions, including detoxification of cytosolic hydrogen peroxide and organic peroxides by means of selenium-dependent GSH peroxydase (Hunt \& Stocker, 1990; Ginsburg \& Atamna, 1994)

The G6PDH deficiency phenotype results in deficiency of NADPH, the substrate of GSH reductase in erythrocytes, and GSH is irreversibly oxidised to the disulfide, resulting in membrane damage and denaturation of $\mathrm{Hb}$ because of its oxidation, and this may also kill the intracellular parasite. G6PDH deficiency, which affects over 400 million people, is the most common enzymopathy in humans. The geographical correlation of its distribution with the historical endemicity of malaria suggests that the frequency of this disorder has risen through natural selection by malaria (Ruwende et al., 1995). On this basis, inhibition of GSH reductase, represents a promising approach for malarial chemotherapy.

Human GSH reductase is one of the most thoroughly studied enzymes, including the three-dimensional structure at $1.5 \mathrm{~A}$ resolution. The enzyme is a homodimer with a 52,000 Mr subunit, with two catalytic sites and amino acids of both protein subunits are involved at each catalytic site. In the reduced form, one of the two active site cysteines (cys 63) form a charge transfer with the flavin ring of FAD. The oxidised form, Eox is characterized by a disulphide bridge between the active site residues cys 58 and cys 63. Reduction of the disulphide with the coenzyme NADPH via the flavin ring results in the formation of dithiol Cys 58-Cys 63. This reduced enzyme EH2 interact with GSSG, leading to the release of two GSH molecules and reoxydation of the active site to complete the catalysis. The better tolerated $\mathrm{HeCNU}$ induces carbamoylation and alkylation of Cys 58 of GSH reductase, and has antimalarial properties in vitro and in animals. Inhibition of the enzyme does not apply to the form of the enzyme normally present in vitro (Eox), but only to the NADPH-reduced EH2 (Schirmer et al., 1995).

\section{IRON DEPRIVATION}

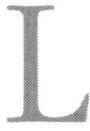
ike all living organisms, malaria parasites need iron for their vital functions and must handle their cellular contents in a highly regulated fashion. Mammalian cells regulate their iron balance through transcriptional and translational control over expression of the storage protein ferritin and transferrin receptor. However, in the asexual stage of growth, parasites present a special case of iron metabolism (Haldar et al., 1986; Pollack et al., 1988; Sanchezlopez et al., 1992; Gabay et al., 1993).

Iron chelation treatments of malaria-parasite infected erythrocytes selectively intervenes with the iron-dependent metabolism of malaria parasites, and have been shown to abolish plasmodial growth in vitro and reduce malaria infection in mice (Fritsch et al., 1985), monkeys (Pollack et al., 1987) and in clinical cases in humans (Traore et al., 1991; Bunnag et al., 1992, Gordeuk et al., 1992, Gordeuk et al., 1993). The in vitro antimalarial action of desferrioxamine (DFO) is manifested after 8-10 h of continuous exposure of $P$. falciparum trophozoites to the drugs (Golenser et al., 1995).

The antimalarial mode of action of iron chelators reside in their ability to penetrate the parasite and sequester their iron. The putative molecular target was assumed to be associated with a central iron-dependent enzyme such as ribonucleotide reductase (see above) in analogy to the proposed mechanism of action of DFO in mammalian cells. It is also possible that DFO might destabilizes the hemozoin pigment via removal of iron, consequently releasing toxic hemederived material (Vanzyl et al., 1993). For hydroxamatetype chelators, antimalarial activity has been attributed to chelation of the internal iron pool, in contrast to others that also remove iron from transferrin. Failure to recover from chelation treatment after replenishment 
of iron to infected cells (including using ion carrier complexes), might indicate that the chelators interfere either directly or indirectly with generation or reconstitution of iron-dependent functions, but not necessarily with iron acquisition per se. This finding is also consistent with evidence that iron chelators act not by iron removal, but rather by blocking iron integration (Lytton et al., 1994). Intracellular iron pools affected by drugs like DFO have been localized within the parasite (Loyevsky et al., 1993), and presumably associated with Hb breakdown (Gabay \& Ginsburg, 1993).

There have been limitations on widespread clinical use of DFO due to the necessary parenteral administration to overcome slow access of the drug to infected cells and rapid washout from body fluids and, above all, frequent relapses in most malaria patients upon discontinuation of the treatment. These limitations led to development of more hydrophobic chelators which, by virtue of their membrane-penetrating character, were considered potentially useful for oral administration. Cabantchick's group improved the antimalarial efficacy of relatively safe DFO chelators by designing more hydrophobic synthetic reversed siderophores (named RSF) and N-terminal-modified DFO which fully retained the iron III binding capacity. Hydrophobic/hydrophilic balance and molecular arrangement have been controlled both by the lipophilic character of an amino acid chain emerging from the basic polyhydroxamate structure, and the length of an aliphatic chain (Cabantchik, 1995). The antimalarial spectra of these two types of iron chelators differ in the speed of action, stage dependence and degree of reversibility of effects. While RSF had similar effects on rings and trophozoites, DFO only had major effects on trophozoites. Furthermore, the effects of DFO on trophozoites were relatively slow to develop but were largely irreversible in nature, whereas those of the RSF were irreversible only on the ring stage but reversible on trophozoites. The authors proposed that these differential efficacies on the various stages reflect not only the drug's permeation properties but also their retention within parasites after drug removal. This consideration is important since only the cytotoxic effects of drugs must be considered. Although DFO is not very permeant to rings, the antimalarial effect was mostly irreversible (parasite growth did not resume after drug removal), and is exclusively manifested in advanced developmental stages, since a substantial fraction of the drug taken up by cells was retained in trophozoites and schizonts even after drug removal. These modes of action also have some implications for their future as curative antimalarial agents. A combination of fast-acting siderophores (which are able to penetrate ring-infected red cells), and slow-acting DFO derivatives (which are only permeable at the early trophozoite/schizont stages), was found to provide a new and efficient means of arresting $P$. falciparum growth in vitro (Golenser et al., 1995; Tsafack et al., 1995).

\section{OTHER POTENTIAL TARGETS}

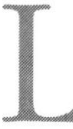

ovastatin and simvastatin, two HMG-CoA reductase inhibitors, possess antiparasitic activities in vitro against $P$. falciparum and $B$. divergens; the trophozoite stage which precedes the $\mathrm{S}$ phase and the nuclear divisions are the most susceptible stage. However, the cytostatic effect could not be excluded and the differential activity is not high enough to expect specificity. In the absence of de novo synthesis of cholesterol, these effects could concern other aspects of the isoprenoid pathway, such as ubiquinones production (Grellier et al., 1994).

Microtubules, a component of the skeletal system within the cell, consist of $\alpha$ and $\beta$ tubulin, each encoded by different but evolutionarily-related gene families, and play an important role in maintaining cell shape, cell movements, cell morphogenesis and intracellular transport. In Plasmodium, microtubules are involved in stabilisation of the inner membrane of gametocytes and of their flagella. They are also probably essential for the spindle pole of the final mitotic division and trafficking of extranuclear vesicles in the blood stages as well as for merozoite morphogenesis and some aspects of invasion (Maessen et al., 1993; Bannister et al., 1995). Microtubular structures contain ing $\alpha$ tubulin have been shown to change their conformation during parasite replication (Read et al., 1993).

The $P$. falciparum genome contains two $\alpha$ tubulin genes and a single $\beta$ tubulin gene. The $\gamma$ tubulin gene is also encoded by the P. falciparum genome. This protein, usually present in the cell in minor amounts, is essential for nuclear division and microtubule assembly, and present substantial differences with host proteins (Maessen et al., 1993).

Taxol, a plant-derived antitumor drug, has a unique mode of action, since it is a mitotic spindle poison, which binds polymerised tubulin, stoichiometrically stabilizes microtubules and inhibits their depolymerisation to free tubulin. The anti-cancer drugs taxol (Pouvelle et al., 1994) and taxotere (Schrevel et al., 1994) both inhibit growth of $P$. falciparum at concentrations ranging from $1 \mu \mathrm{M}-0.1 \mu \mathrm{M}$. It is unclear whether these inhibitors act on host or parasite factors, but the former could clear parasitemia of $P$. chabaudi infected mice. However, side-effects of these antitumor compounds restrict their use to the treatment of life-threatening diseases. 
The dinitroaniline, trifluraline (at micromolar concentration) selectively binds to microtubules in malaria parasites, and disrupts their structure, inhibiting growth and differentiation of the blood stage and blocking maturation and extraflagellation of gametocytes. The drug has no or very low affinity for mammalian tubulin or microtubules, and does not affect the viability of mammalian cells (Kaidoh et al., 1995). This specificity has great potential for antimalarial agents of therapeutic value. Moreover, the fact that both sexual and asexual stages of P. falciparum contain microtubular structures which play a crucial role in structural integrity, nuclear division and parasite differentiation, highlight the special interest of these targets.

In conclusion, the future of antimalarial chemotherapy is particularly cloudy in view of the spread of parasite crossresistance to drugs that are not even structurally or pharmacologically related. The first reason for this disaster is that the range of antimalarial drugs used is far too small. Only new pharmacological models will make it possible to select molecules with novel mechanisms of action, thus delaying resistance. It is also evident that all approaches are not equally promising, since the actual target is not always indispensable for Plasmodium, or because it is difficult to achieve the necessary therapeutic specificity. In addition, many agents only act on the intracellular parasite over a relatively short time window, thus limiting the applicability of such agents. A possible mechanism of improving the therapeutic potential is increasing their accessibility to parasites, by augmenting the drug retention by the parasite to ensure more persistent cytotoxic effects (by application of a more permeant prodrugs), or by application of a combination of drugs with different action profiles. New highly active compounds also have to satisfy a long list of criteria including bioavailability, metabolic stability, synthetic tractability, toxicity and, last but not the least, profitability. This scheme seems quite simple, but progressing sequentially through these steps is very important when developing a pharmacological model. Indeed, and unfortunately, all the criteria described must be satisfied for any approach to succeed.

\section{ACKNOWLEDGEMENTS}

I am especially grateful to Daniel Dive, Catherine Braun Breton and Hye Jeong Yeo for reading the manuscript. The phospholipid model was developed with the following partners who are gratefully acknowledged: M.L. Ancelin, M. Calas \& L. Giral (University of Montpellier II, France), A. Thomas \& C. Janse (BPRC-TNO, Netherlands), W. Peters (International Institute of Parasitology, St Albans, UK), C. Slomianny
(INSERM, Lille, France), S. Herrera (Universitad del Valle, Cali, Colombia), F. Louis \& P. Ringwald (OCEAC, Yaoundé, Cameroon), and J. Bourguignon (CNRS, Strasbourg, France). These studies were supported by the European Union within the framework of the Science and Technology for Development program (Contract TS3*-CT92.0084), the UNDP/World Bank/WHO Special Programme for Research and Training in Tropical Diseases (Grant 950165), the VIRBAC group (Nice, France), CNRS (GDR 1077, Etudes des parasites pathogènes), and the French Ministère de la Recherche (DSPT $\mathrm{N}^{\circ}$ ).

\section{REFERENCES}

Ancelin M.L., Parent M., Thuet M.J., Philippot J.R. \& Vial H.J. Increased permeability to choline in simian erythrocytes after Plasmodium knowlesi infection. Biochemical Journal, 1991, 701-709.

ANCELIN M.L. \& VIAL H.J. Quaternary ammonium compounds efficiently inhibit Plasmodium falciparum growth in vivo by impairment of choline transport. Antimicrobial Agents and Chemotherapy, 1986, 814-820.

AnCELIN M.L. \& Vial H.J. Regulation of phosphatidylcholine biosynthesis in Plasmodium-infected erythrocytes. Biochimica et Biophysica Acta, 1989, 82-89.

Ancelin M.L., Vial H.J. \& Philippot J.R. Inhibitors of choline transport into Plasmodium-infected erythrocytes are effective antiplasmodial compounds in vitro. Biochemical Pharmacology, 1985, 4068-4071.

ANDREws P. Functional groups drug-receptor interactions and drug design. Trends in Pharmaceutical Science, 1986, 148151 .

Asawamahasakda W., Ittarat I., Pu Y.M., Ziffer H. \& MeshNICK S.R. Reaction of antimalarial endoperoxides with specific parasite proteins, Antimicrobial Agents and Chemotherapy, 1994, 1854-1858.

Atamna H. \& Ginsburg $H$. Origin of reactive oxygen species in erythrocytes infected with Plasmodium falciparum. Molecular and Biochemical Parasitolology, 1993, 231-242.

Atamna H., Pascarmona G. \& Ginsburg H. Hexose-monophosphate shunt activity in intact Plasmodium falciparum infected erythrocytes and in free parasites. Molecular and Biochemical Parasitology, 1994, 79-89.

Bailly E., Jambou R., SAvel J. \& Jaureguiberry G. Plasmodium falciparum - Differential Sensitivity in vitro to E-64 (Cysteine Protease Inhibitor) and Pepstatin-A (Aspartyl Protease Inhibitor). Journal of Protozoology, 1992, 593-599.

Bannister L.H. \& Mitchell G.H. The role of the cytoskeleton in Plasmodium falciparum merozoite biology: An electronmicroscopic view. Annals of Tropical Medicine and Parasitology, 1995, 105-111.

Beaumelle B.D. \& Vial H.J. Correlation of the efficiency of fatty derivatives in suppressing Plasmodium falciparum growth in culture with their inhibitory effect on acyl-CoA synthetase activity. Molecular and Biochemical Parasito$\log y, 1988,39-42$. 
Becuwe P., Slomianny C., Camus D. \& Dive D. Presence of an endogenous superoxide dismutase activity in 3 rodent malaria species. Parasitology Research, 1993, 349-352.

Beutler E. G6PD deficiency. Blood, 1994, 3613-3636.

Breton C.B., Blisnick T., Jouin H., Barale J.C., Rabilloud T. et al. Plasmodium chabaudi p68 Serine Protease Activity Required for Merozoite Entry into Mouse Erythrocytes. Proceedings of the National Academy of Sciences USA, 1992, 9647-9651.

Breton C.B. \& Peirera da Silva L.H. Plasmodium and the Infected Erythrocyte - Malaria Proteases and Red Blood Cell Invasion. Parasitology Today, 1993, 92-96.

Brooks D.R., Wang P., Read M., Watkins W.M., Sims P.F.G. et al. Sequence variation of the hydroxymethyldihydropterin pyrophosphokinase: Dihydropteroate synthase gene in line so the human malaria parasite, Plasmodium falciparum, with differing resistance to sulfadoxine. European Journal of Biochemistry, 1994, 397-405.

Buffinton G.D., Hunt N., Cowden W. \& Clark A. Malaria: a role for reactive oxygen species in parasite killing and host pathology in Free radicals, Cell damage and Disease. Rice-Evans C., ed. Richelieu Press, London, 1986, 201-220.

Bunnag D., Poltera A.A., Viravan C., Looareesuwan S., HariNASUTA K.T. et al. Plasmodicidal Effect of Desferrioxamine-B in Human Vivax or Falciparum malaria from Thailand. Acta Tropica, 1992, 59-67.

Bzik D.J., Fox B.A. \& GONYER K. Expression of PlasmodiumFalciparum Lactate Dehydrogenase in Escherichia-Coli. Molecular and Biochemical Parasitology, 1993, 155-166.

CABANTCHIK Z.I. Altered membrane transport of malariainfected erythrocytes: A possible pharmacological target, Blood, 1989, 1464-1471.

CABANTCHIK Z.I. Iron chelators as antimalarials: The biochemical basis of selective cytotoxicity. Parasitology Today, 1995, 74-78

Chakrabarti D., Schuster S.M. \& Chakrabarti R. Cloning and Characterization of Subunit Genes of Ribonucleotide Reductase, a Cell-Cycle-Regulated Enzyme, from Plasmodium falciparum. Proceedings of the National Academy of Sciences USA, 1993, 12020-12024.

Chavalitshewinkoon P., Devries E., Stam J.G., Franssen F.F.J., VANDERVliet P.C. et al. Purification and Characterization of DNA Polymerases from Plasmodium falciparum. Molecular and Biochemical Parasitology, 1993, 243-253.

Clark D., Chrisey J., Campbell E. \& Davidson E. Nonsequence-specific antimalarial activity of oligodeoxynucleotides. Molecular and Biochemical Parasitology, 1994, 129-134.

Clemens M. \& Waller H. Lipid peroxydation in erythrocytes. Chemistry and Physics of Lipids, 1987, 251-268.

Collins F. \& PASKEwITZ M. Malaria: current and future prospects for control. Annales de la Revue d'Entomologie, 1995, 195-219.

CoOmber D.W.J., Osullivan W.J. \& Gero A.M. Adenosine Analogues as Antimetabolites Against Plasmodium falciparum Malaria. International Journal for Parasitology, 1994, 357-365.

Cowman A.F. \& FoOTE S.J. Chemotherapy and drug resistance in malaria. International Journal for Parasitology, 1990, 503-513

Delplace P., Bhatia A., Cagnard M., Camus D. \& Colombet G. Protein 126: a parasitophorous vacuole antigen associated with the release of Plasmodium falciparum merozoites, Biol. Cell., 1986, 215-221.

Dorn A., Stoffel R., Matile H., Bubendorf A. \& Ridley R.G. Malarial haemozoin beta-haematin supports haem polymerization in the absence of protein. Nature, 1995, 269271

Eads J., Scapin G., Xu Y., Grubmeyer C. \& Sacchettini J. The crystal structure of human hypoxanthine-guanosine phosphoribosyltransferase with bound GMP. Cell, 1994, 325334.

Eakin A.E., Nievesalicea R., Tosadoacevedo R., Chin M.S., WANG C.C. et al. Comparative complement selection in bacteria enables screening for lead compounds targeted to a purine salvage enzyme of parasites. Antimicrobial Agents and Chemotherapy, 1995, 620-625.

Elford B., Cowan G. \& Ferguson D. Parasite-regulated membrane transport processes and metabolic control in malariainfected-erythrocytes. Biochemical Journal, 1995, 361-374.

ELLIS J.E. Coenzyme Q homologs in parasitic protozoa as targets for chemotherapeutic attack. Parasitology Today, 1994, 296-301.

Fairfield A., Abosch A., Ranz A., Eaton J. \& Meshnick S. Oxidant defense enzymes of Plasmodium falciparum. Molecular and Biochemical Parasitology, 1988, 77-82.

Flores M.V.C., OSUlLIVAN W.J. \& STEWART T.S. Characterisation of the carbamoyl phosphate synthetase gene from Plasmodium falciparum. Molecular and Biochemical Parasitology, 1994, 315-318.

Fowler R., Sinden R. \& PUDNEY M. Inhibitory activity of the anti-malarial atovaquone $(566 \mathrm{C} 80)$ against ookinetes, oocysts, and sporozoites of Plasmodium berghei. Journal of Parasitology, 1995, 452-458.

Francis S.E., Gluzman I.Y., Oksman A., Knickerbocker A., Mueller R. et al. Molecular characterization and inhibition of a Plasmodium falciparum aspartic protease. EMBO Journal, 1994, 306-317.

Fritsch G., Treumer J., Spira D. \& Jung A. Plasmodium vinckei: suppression of mouse infections with desferrioxamine B Experimental Parasitology. Experimental Parasitology, 1985, 171-176.

FRY M. \& PUDNEY M. Site of action of the antimalarial hydroxynaphtoquinone, 566C80. Biochemical Pharmacology, 1992.

GABAY T. \& GinsBURG H. Hemoglobin denaturation and iron release in acidified red blood cell lysate - a possible source of iron for intraerythrocytic malaria parasites. Experimental Parasitology, 1993, 261-272.

Gabay T., Krugliak M., Shalmiev G. \& Ginsburg H. Inhibition by anti-malarial drugs of haemoglobin denaturation and iron release in acidified red blood cell lysates. A possible mechanism of their antimalarial effect. Parasitology, 1994, 371-381.

Gamage S., Tepsiri N., Wilairat P., Wojcik S., Figgit P. et al. Synthesis and in vitro evaluation of 9-anilino-3,6-diami- 
noacridines active against a multidrug-resistant strain of the malaria-parasite Plasmodium falciparum. Journal of Medicinal Chemistry, 1994, 1486-1494.

Gati W.P., A.N. L., Wang T.I., Young J.D. \& Paterson A.R. Parasite-induced processes for adenosine permeation in mouse erythrocytes infected with the malarial parasite Plasmodium yoelii. Biochemical Journal, 1990, 277-280.

Gero A.M. \& KirK K. Nutrient transport pathways in Plasmodium infected erythrocytes: What and where are they? Parasitology Today, 1994, 395-399.

Gero A.M. \& O'Sullivan W.J. Purines and Pyrimidines in Malarial Parasites. Blood Cells, 1990, 467-484.

Gero A.M. \& Upston J.M. Altered membrane permeability: a new approach to malaria chemotherapy. Parasitology Today, 1992, 283-286.

Ginsburg H. Malaria and the red blood cell, Vol. 16. Springer International, Wien, 1990, $628 \mathrm{p}$.

Ginsburg H. \& Atamna H. The redox status of malariainfected erythrocytes: an overview with an emphasis on unresolved problem. Parasite, 1994, 5-13.

Ginsburg H., Gorodetsky R. \& Krugliak M. The status of zinc in malaria (Plasmodium falciparum) infected human red blood cells: stage-dependent accumulation, compartmentation and the effect of dipicolinate. Biochimica et Biophysica Acta, 1986, 337-344.

Gluzman I.Y., Francis S.E., Oksman A., Smith C., Duffin K. et al. Order and specificity of the Plasmodium hemoglobin degradation pathways. Journal of Clinical Investigation, 1994, 1602-1607.

GoldBerg D.E. Plasmodial Hemoglobin Degradation - An Ordered Pathway in a Specialized Organelle. Infectious Agent Diseases, 1992, 207-211

Golenser J. \& Chevion M. Oxidant stress and malaria: hostparasite interrelationships in normal and abnormal erythrocytes. Seminars in Hematology, 1989, 313-325.

Golenser J., Tsafack A., Amichai Y., Libman J., Shanzer A. et al. Antimalarial action of hydroxamate-based iron chelators and potentiation of desferrioxamine action by reversed siderophores. Antimicrobial Agents and Chemotherapy, 1995, 61-65.

Gordeuk V., Thuma P., Brittenham G., Mclaren C., Parry D. et al. Effect of Iron Chelation Therapy on Recovery from Deep Coma in Children with Cerebral Malaria. New England Journal of Medicine, 1992, 1473-1477.

Gordeuk V.R., Thuma P.E., Brittenham G.M., Biemba G., Zulu S. et al. Iron Chelation as a Chemotherapeutic Strategy for Falciparum malaria. American Journal of Tropical Medicine and Hygiene, 1993, 193-197.

Grellier P., Valentin A., Millerioux V., Schrevel J. \& RigoMIER D. 3-Hydroxy-3-Methylglutaryl Coenzyme a Reductase Inhibitors Lovastatin and Simvastatin Inhibit in vitro Development of Plasmodium falciparum and Babesia Divergens in Human Erythrocytes. Antimicrobial Agents and Chemotherapy, 1994, 1144-1148.

Haldar K., Henderson C. \& Cross G. Identification of the parasite transferrin receptors of $P$. falciparum infected erythrocytes and its acylation via 1,2-diacyl-sn-glycerol. Pro- ceedings of the National Academy of Sciences USA, 1986, 8565-8569

Hien T.T. \& White N.J. Qinghaosu. Lancet, 1993, 603-608

Holder A.A., Blackman M.J., Borre M., Burghaus P.A., Chappel J.A. et al. Malaria parasites and erythrocyte invasion. Biochemical Society Transactions, 1994, 291-295.

Holz G.G. Lipids and the malaria parasite. Bulletin of the WHO, 1977, 237-248.

Hudson A.T. Atovaquone. A novel broad-spectrum anti-infective drug. Parasitology Today, 1993, 66-68.

Hunt N.H. \& STOCKER R. Oxidative stress and the redox status of malaria-infected erythrocytes. Blood Cells, 1990, 499-526.

James E. Superoxyde dismutase. Parasitology Today, 1994, 481-484.

Kaidoh T., Nath J., Fujioka H., Okoye V. \& Aikawa M. Effect and localization of trifluralin in Plasmodium falciparum gametocytes: An electron microscopic study. The Journal of Eukaryotic Microbiology, 1995, 61-64.

Kamchonwongpaisan S., Vanitchareon N. \& Yuthavong Y. The Mechanism of Antimalarial Action of Artemisinin (Qinghaosu). In: Lipid. Soluble Antioxidants: Biochemistry and Clinical Applications. (Ong A.S.H. \& Packer L., eds.), Birkhauser Verlag, Basel, 1992, 363-372.

King A. \& Melton D.W. Characterization of cDNA clones for hypoxanthine-guanine phosphoribosyltransferase from the human malarial parasites, P. falciparum: comlparison to the mammalain gene and protein. Nucleic Acids Research, 1987, 10469-10481.

Krogstad D.J., Suzuki M., Long C.A., Aoki Y., Ishil A. et al. Drug discovery, development and deployment: A report from the 28th joint conference of the US-Japan Parasitic Diseases Panels, Baltimore, Maryland, July 1993. American Journal of Tropical Medicine and Hygiene, 1994, 384-388.

KRUNGKRAI J. Purification, characterization and localization of mitochondrial dihydroorotate dehydrogenase in Plasmodium falciparum, human malaria parasite. Biochimica et Biophysica Acta, 1995, 351-360.

Krungkrai S.R. \& Yuthavong Y. The antimalarial action on Plasmodium falciparum of qinghaosu and artesunate in combination with agents which modulates oxidant stress. Transactions of the Royal Society of Tropical Medicine and Hygiene, 1987, 710-714.

Loyevsky M., Lytton S.D., Mester B., Libman J., Shanzer A. et al. The Antimalarial Action of Desferal Involves a Direct Access Route to Erythrocytic (Plasmodium falciparum) Parasites. Journal of Clinical Investigation, 1993, 218-224.

Lytton S.D., Mester B., Libman J., Shanzer A. \& Cabantchik Z.I. Mode of action of iron (III) chelators as antimalarials. 2. Evidence for differential effects on parasite iron-dependent nucleic acid synthesis. Blood, 1994, 910-915.

Maessen S., Wesseling J.G., Smits M.A., Konings R.N.H. \& Schoenmakers J.G.G. The gamma-Tubulin Gene of the Malaria Parasite Plasmodium falciparum. Molecular and Biochemical Parasitology, 1993, 27-36.

Martin S.K. The malaria/G6PD hypothesis revisited. Parasitology Today, 1994, 251-252. 
Maurice J. Malaria vaccine raises a dilemma. Science, 1995 320-323.

McConkey G.A., Ittarat I., Meshnick S.R. \& McCutchan T.F. Auxotrophs of Plasmodium falciparum dependent on paminobenzoic acid for growth. Proceedings of the National Academy of Sciences USA, 1994, 4244-4248.

McKerrow J.H., Sun E., Rosenthal P.J. \& Bouvier J. The Proteases and Pathogenicity of Parasitic Protozoa. Annual Review of Microbiology, 1993, 821-853.

Meshnick S.R. The mode of action of antimalarial endoperoxides. Transactions of the Royal Society of Tropical Medicine and Hygiene, 1994, 31-32.

Meshnick S.R., Ranz A., Thomas A., Xu C.M. \& Pan H.Z. Artemisinin (qinghaosu): the role of hemin in its mechanism of antimalarial action. Molecular and Biochemical Parasitology, 1991, 181-190.

Meshnick S.R., Yang Y.Z., Lima V., Kuypers F., Kamchonwongpaisan S. et al. Iron-Dependent Free Radical Generation from the Antimalarial Agent Artemisinin (Qinghaosu). Antimicrobial Agents and Chemotherapy, 1993, $1108-1114$

Moll G.N., Van den Eertwegh V., Tournois H., Roelofsen B., Op DEN Kamp J.A.B. et al. Growth inhibition of Plasmodium falciparum in vitro cultures by selective action of trytophan-N-formylated gramicidin incorporated in lipid vesicles. Biochimica et Biophysica Acta, 1991, 206210 .

Muhia D.K., Thomas C.G., Ward S.A., Edwards G., Mberu E.K. et al. Ferriprotoporphyrin catalysed decomposition of artemether: Analytical and pharmacological implications. Biochemical Pharmacology, 1994, 889-895.

Nakornchai S. \& Anantavara S. Oxygen free radicals in malaria. In: Lipid-Soluble Antioxidants. Biochemistry and Clinical Applications. Ong A.S.H. Packer L. (eds), Birkhauser Verlag, Basel, 1992, 355-362.

Olliaro P. \& Goldberg D. The Plasmodium digestive vacuole: metabolic headquarters and choice drug target. Parasito$\log y$ Today, 1995, 294-297

Oluiaro P. \& Trigg P. Status of antimalarial drugs under development. Bulletin of the WHO, 1995, 565-571.

Phil.tipson J.D. Natural products as drugs. Transactions of the Royal Society of Tropical Medicine and Hygiene, 1994, 1719

Pollack S., Rosan D., Davidson D. \& Escajadillo A. Desferrioxamine suppresses $P$. falciparum in Aotus monkeys. Proc. Soc. Exp. Biol. Med., 1987, 162-164.

Pollack S. \& Schnelle. Inability to detect transferrin receptors on P. falciparum parasitized red cells. British Journal of Haematology, 1988, 125-129.

Posner G.H., Oh C.H., Webster H.K., Ager A.L. \& Rossan R.N. New, antimalarial, tricyclic 1,2,4-trioxanes: Evaluations in mice and monkeys. American Journal of Tropical Medicine and Hygiene, 1994, 522-526.

Pouvelle B., Farley P.J., Long C.A. \& Taraschi T.F. Taxol arrests the development of blood-stage Plasmodium falciparum in vitro and Plasmodium chabaudi adami in malaria-infected mice. Journal of Clinical Investigation, 1994, 413-417

Pussard E. \& Verder F. Antimalarial 4-Aminoquinolines Mode of Action and Pharmacokinetics. Fundamental and Clinical Pharmacology, 1994, 1-17.

QUEEN S., JAFT D. \& REYES P. Characterization of adenine phosphoribosyltransferase from the human malaria parasite, Plasmodium falciparum. Biochimica et Biophysica Acta, 1989, 160-165

Ranz A. \& Meshnick S. Plasmodium falciparum inhibitor sensitivity of the endogenous superoxide dismutase. Experimental Parasitology, 1989, 125-128.

Rathod P.K., Khosla M., Gassis S., Young R.D. \& Lutz C. Selection and characterization of 5-fluoroorotate-resistant Plasmodium falciparum. Antimicrobial Agents and Chemotherapy, 1994, 2871-2876.

Rathod P.K. \& Reshmi S. Susceptibility of Plasmodium Falciparum to a Combination of Thymidine and ICI D1694, a Quinazoline Antifolate Directed at Thymidylate Synthase. Antimicrobial Agents and Chemotherapy, 1994, 476480 .

Read M., Sherwin T., Holloway S.P., Gull K. \& Hyde J.E. Microtubular Organization Visualized by Immunofluorescence Microscopy During Erythrocytic Schizogony in Plasmodium falciparum and Investigation of Post-Translational Modifications of Parasite Tubulin. Parasitology, 1993, 223-232.

Riou J., Gabillot M., Philippe M., Schrevel J. \& Riou G. Purification and characterization of Plasmodium berghei DNA topoisomerase I and II: drug action, inhibition of decatenation and relaxation, and stimulation of DNA cleavage. Biochemistry, 1986, 1471-1479

Roose J.P. \& VAnNoorden C.J.F. Synthetic protease inhibitors: Promising compounds to arrest pathobiologic processes. Journal of Laboratory and Clinical Medicine, 1995, 433-441.

Rosenthal P., Lee G. \& Smith R. Inhibition of a Plasmodium vinckei cysteine proteinase cures malaria. Journal of Clinical Investigation, 1993, 1052-1056.

Rosenthal P.J. Plasmodium falciparum: Effects of proteinase inhibitors on globin hydrolysis by cultured malaria parasites. Experimental Parasitology, 1995, 272-281

Rosenthal P.J. \& Nelson R.G. Isolation and characterization of a cysteine protease gene of Plasmodium falciparum. Molecular and Biochemical Parasitology, 1992, 143-152.

Rosenthal P.J., Ring C.S., Chen X.W. \& Cohen F.E. Characterization of a Plasmodium vivax cysteine proteinase gene identifies uniquely conserved amino acids that may mediate the substrate specificity of malarial hemoglobinases. Journal of Molecular Biology, 1994, 312-316.

Rosenthal P.J., Wollish W.S., Palmer J.T. \& Rasnick D. Antimalarial Effects of Peptide Inhibitors of a Plasmodium falciparum Cysteine Proteinase. Journal of Clinical Investigation, 1991, 1467-1472.

Roтн E.J. Plasmodium falciparum carbohydrate metabolism: a connection between host and parasite. Blood Cells, 1990, 453-460. 
Rubin H., Salem J.S., Li L.S., Yang F.D., Mama S. et al. Cloning, Sequence Determination, and Regulation of the Ribonucleotide Reductase Subunits from Plasmodium falciparum. A Target for Antimalarial Therapy. Proceedings of the National Academy of Sciences USA, 1993, 9280-9284.

Ruwende C., Khoo S., Snow R., Yates S., Kwiatkowski D. et al. Natural selection of hemi-and heterozygotes for G6PD deficiency in Africa by resistance to severe malaria. Nature, 1995, 246-249.

Salas F., Fichmann J., Lee G.K., Scott M.D. \& Rosenthal P.J. Functional expression of falcipain, a Plasmodium falciparum cysteine proteinase, supports its role as a malarial hemoglobinase. Infection and Immunity, 1995, 2120-2125.

SANCHEzlopez R. \& HaldaR K. A Transferrin-Independent Iron Uptake Activity in Plasmodium-Falciparum-Infected and Uninfected Erythrocytes. Molecular and Biochemical Parasitology, 1992, 9-20

Sano G., Morimatsu K. \& Hori T. Purification and Characterization of Dihydrofolate Reductase of Plasmodium falciparum Expressed by a Synthetic Gene in Escherichia coli. Molecular and Biochemical Parasitology, 1994, 265273 .

Schirmer R.H., Muller J.G. \& Krauthsiegel R.L. Disulfidereductase inhibitors as chemotherapeutic agents: The design of drugs for trypanosomiasis and malaria. Angew Chem Int Ed, 1995, 141-154.

Schlesinger P., Krogstad D. \& Herwaldt B. Antimalarial agents: mechanism of action, Antimicrobial Agents and Chemotherapy, 1988, 793-798.

Schrevel J., Deguercy A., Meyer R. \& Monsigny M. Proteases in malaria-infected red cells. Blood Cells, 1990, 563-584.

Schrevel J., Sinou V., Grellier P., Frappier F., Guenard D. et al. Interactions between docetaxel (Taxotere) and Plasmodium falciparum-infected erythrocytes. Proceedings of National Academy of Sciences USA, 1994, 8472-8476.

Scott M.D., Meshnick S.R., Williams R.A., Chiu D.T.Y., Pan H.C. et al. Quinghaosu-mediated oxidation in normal and abnormal erythrocytes. Journal of Laboratory and Clinical Medicine, 1989, 401-406.

Seymour K.K., Lyons S.D., Phillips L., Rieckmann K.H. \& Christopherson R.I. Cytotoxic Effects of Inhibitors of de novo Pyrimidine Biosynthesis upon Plasmodium falciparu. Biochemistry, 1994, 5268-5274.

SHERMAN I. Biochemistry of Plasmodium (malarial parasite), Microbiology Review, 1979, 453-495.

SHERMAN I.W. Metabolism, In: Peters W. and Richards W. (eds). Springer Verlag, Berlin, 1984, 31-71.

Silphen J., YANAi P. \& CaBANTChiK Z.I. Bioflavonoid effects on in vitro cultures of Plasmodium falciparum. Inhibition of permeation pathways induced in the host cell membrane by the intraerythrocytic parasite. Biochemical Pharmaco$\log y, 1988,4269-4276$.

Simoes A.P.C.F., Vanderberg J.J.M., Roelofsen B. \& OpdenKamP J.A.F. Lipid peroxidation in Plasmodium falciparum parasitized human erythrocytes. Archives of Biochemistry and Biophysics, 1992, 651-657.
Sirawaraporn W., Prapunwattana P., Sirawaraporn R., Yuthavong Y. \& SANTI D.V. The Dihydrofolate Reductase Domain of Plasmodium falciparum Thymidylate Synthase-Dihydrofolate Reductase-Gene Synthesis, Expression, and AntiFolate-Resistant Mutants. Journal of Biological Chemistry, 1993, 21637-21644.

Slater A.F.G. \& Cerami A. Inhibition by chloroquine of a novel haem polymerase enzyme activity in malaria trophozoites. Nature, 1992, 167-169

Smeijsters L.J.J.W., Zijlstra N.M., Devries E., Franssen F.F.J., JANSE C.J. et al. The effect of (S)-9-(3-hydroxy-2-phosphonylmethoxypropyl) adenine on nuclear and organellar DNA synthesis in erythrocytic schizogony in malaria. Molecular and Biochemical Parasitology, 1994, 115-124.

SPENCER C. \& KL G. Atovaquone. A review of its pharmacological properties and therapeutic efficacy in Opportunistis Infections. Drugs, 1995, 176-196.

Sun E. \& COHEn F.E. Computer-Assisted Drug Discovery. A Review. Gene, 1993, 127-132.

Tanner M., Teuscher T. \& Alonso P.L. SPf66 - The first malaria vaccine. Parasitology Today, 1995, 10-13.

Traore O., Carnevale P., Kaptue N., Bede J., Desfontaine J. et al. Preliminary reporst on the use of desferrioxamine in the treatment of Plasmodium falciparum malaria. American of Journal of Hematology, 1991, 206-208.

TRIglia T. \& Cowman A.F. Primary structure and expression of the dihydropteroate synthetase gene of Plasmodium falciparum. Proceedings of the National Academy of Sciences USA, 1994, 7149-7153.

Tsafack A., Golenser J., Libman J., Shanzer A. \& Cabantchik Z.I. Mode of action of iron(III) chelators as antimalarials. 3. Overadditive effects in the combined action of hydroxamate-based agents on in vitro growth of Plasmodium falciparum. Molecular Pharmacology, 1995, 403-409.

Turrini F., Ginsburg H., Bussolino F., Pescarmona G.P., Serra M.V. et al. Phagocytosis of Plasmodium falciparum infected human red blood cells by human monocytesinvolvement of immune and nonimmune determinants and dependence on parasite developmental stage. Blood, 1992, 801-808.

Ullman B. \& CARTER D. Hypoxanthine-guanine phosphoribosyltransferase as a therapeutic target in protozoal infections. Infectious Agent Diseases, 1995, 29-40.

Vaidya A.B., Lashgari M.S., Pologe L.G. \& Morrisey J. Structural Features of Plasmodium Cytochrome-b That May Underlie Susceptibility to 8-Aminoquinolines and Hydroxynaphthoquinones. Molecular and Biochemical Parasito$\log y, 1993,33-42$.

VAN DyKe K. Purines and pyrimidines in malarial parasitescommentary. Blood Cells, 1990, 485-495.

Vanzyl R.L., Havlik I., Hempelmann E., Macphail A.P. \& McNaMARA L. Malaria Pigment and Extracellular Iron - Possible Target for Iron Chelating Agents. Biochemical Pharmacology, 1993,

Vasanthakumar G., Davis R.L., Sullivan M.A. \& Donahue J. Cloning and expression in Escherichia coli of a hypoxanthine-guanine phosphoribosyltransferase-encoding cDNA from Plasmodium falciparum. Gene, 1991, 63-69. 
Vennerstrom J.L. \& Eaton J.W. Oxidants, oxidant drugs, and malaria. Journal of Medicinal Chemistry, 1988, 1269-1277.

VIAL H.J. \& ANCELIN M.L. Malarial Lipids, an overview, In: Subcellular Biochemistry. Avila J.L. \& Harris J.R. (eds), Plenum Press, New York, 1992, 259-306.

Vial H.J., Ancelin M.L., Philippot J.R. \& Thuet M.J. Biosynthesis and Dynamics of lipids in Plasmodium infected mature mammalian erythrocytes. Blood Cells, 1990, 531-555.

Vial H.J., Thuet M.J., Ancelin M.L., Philippot J.R. \& Chavis C. Phospholipid metabolism as a new target for malaria chemotherapy. Mecanism of action of D-2-amino-1-butanol. Biochemical Pharmacology, 1984, 2761-2770.

Wang P., Brooks D.R., Sims P.F.G. \& Hyde J.E. A mutationspecific PCR system to detect sequence variation in the dihydropteroate synthetase gene of Plasmodium falciparum. Molecular and Biochemical Parasitology, 1995, $115-125$.

WANG T.F. Eukaryotic DNA polymerases. Annual Review of Biochemistry, 1991, 513-532.

WEI N.M. \& SADRZADEH S.M.H. Enhancement of hemininduced membrane damage by artemisinin. Biochemical Pharmacology, 1994, 737-741.

Wellems T.E. Molecular genetics of drug resistance in Plasmodium falciparum malaria. Parasitology Today, 1991, 110-121.

Werndorfer W.H. \& PAYNe D. The dynamics of drug resistance in Plasmodium falciparum. Pharmaceutical Therapy, 1991, 95-121.

White J.H., Kilbey B.J., Devries E., Goman M., Alano P. et al. The Gene Encoding DNA Polymerase-alpha from Plasmodium falciparum. Nucleic Acids Research, 1993, 36433646.

White N.J. Antimalarial pharmacokinetics and treatment regimens. British Journal of Clinical Pharmacology, 1992, 110 .

Woerdenbag H.J., Pras N., Vanuden W., Wallaart T.E., Beekman A.C. et al. Progress in the Research of Artemisinin-Related Antimalarials - An Update. Pharmacology World Sciences, 1994, 169-180.

YANG Y.Z., LitTLE B. \& Meshnick S.R. Alkylation of proteins by artemisinin. Effects of heme, $\mathrm{pH}$, and drug structure. Biochemical Pharmacology, 1994, 569-573.

Zhang F., Gosser D. \& Meshnick S.R. Hemin-catalyzed decomposition of artemisinin (qinghaosu). Biochemical Pharmacology, 1992, 1805-1809. 